IZA DP No. 4721

Changes in Job Stability:

Evidence from Lifetime Job Histories

Miikka Rokkanen

Roope Uusitalo

January 2010 


\title{
Changes in Job Stability: Evidence from Lifetime Job Histories
}

\author{
Miikka Rokkanen \\ MIT \\ Roope Uusitalo \\ Government Institute for Economic Research (VATT) \\ and IZA
}

\section{Discussion Paper No. 4721 \\ January 2010}

IZA

P.O. Box 7240

53072 Bonn

Germany

Phone: $+49-228-3894-0$

Fax: +49-228-3894-180

E-mail: iza@iza.org

\begin{abstract}
Any opinions expressed here are those of the author(s) and not those of IZA. Research published in this series may include views on policy, but the institute itself takes no institutional policy positions.

The Institute for the Study of Labor (IZA) in Bonn is a local and virtual international research center and a place of communication between science, politics and business. IZA is an independent nonprofit organization supported by Deutsche Post Foundation. The center is associated with the University of Bonn and offers a stimulating research environment through its international network, workshops and conferences, data service, project support, research visits and doctoral program. IZA engages in (i) original and internationally competitive research in all fields of labor economics, (ii) development of policy concepts, and (iii) dissemination of research results and concepts to the interested public.
\end{abstract}

IZA Discussion Papers often represent preliminary work and are circulated to encourage discussion. Citation of such a paper should account for its provisional character. A revised version may be available directly from the author. 
IZA Discussion Paper No. 4721

January 2010

\section{ABSTRACT}

\section{Changes in Job Stability: Evidence from Lifetime Job Histories ${ }^{*}$}

We use lifetime job histories from the pension records to evaluate changes in job stability in Finland between 1963 and 2004. We specify a duration model and estimate the effects of elapsed duration, age, and calendar time on the hazard of job ending using individual-level panel data spanning over four decades. We find that this hazard increased during the recession years in the early 1990s but has now returned to the level that prevailed in the 1970s. We also demonstrate that the fluctuations in the hazard rate together with the changes in labor market entry rates have complicated dynamic effects on the tenure distribution, and that analysing the changes in job stability based on the elapsed duration of ongoing jobs may be quite misleading.

JEL Classification: J63

Keywords: job stability, duration model

Corresponding author:

Roope Uusitalo

Government Institute for Economic Research

Arkadiankatu 7

PO Box 1279

00101 Helsinki

Finland

E-mail: roope.uusitalo@vatt.fi

\footnotetext{
* This project has been mainly funded by the Finnish Work Environment Fund and is a part of research program WORK of the Academy of Finland. We are thankful to Mikko Kautto, Arto Laesvuori and Janne Salonen from the Finnish Centre for Pensions for help in accessing the pension contribution data used in the paper and for their detailed comments. We also thank Marko Terviö and Tomi Kyyrä for their suggestions and the participants of Nordic Summer Institute and EALE and SOLE conferences in 2009 for useful comments. All remaining errors, omissions and misinterpretations are ours.
} 


\section{Introduction}

There is now a relatively large literature on the changes in job stability and on the incidence of lifetime jobs in the economy. A general conclusion from the existing studies is that changes in job stability were small up to the mid 1990s (e.g. Neumark 2000, Burgess \& Rees 1996), but during the more recent years job stability has declined (e.g. Farber 2007, Gregg \& Wadsworth 2002). While the majority of existing studies are based on the US data, there are also several studies describing the trends in job durations in European countries. A cross-country study by OECD (2007) is probably the most recent source of comparative data across countries. We use data from Finland that could be considered as a typical European country in terms of job stability. According to the Eurostat Labor Force survey, job stability, measured by the average job tenure, was 9.9 years in Finland in 2005 which was only slightly higher than the unweighted EU average of 9.7 years.

A common problem in most existing studies of job stability is that genuine panel data where job spells could be followed over their entire span is generally lacking. This prevents modelling job durations using standard methods of survival analysis. Instead, researchers have examined the changes in the distribution of elapsed duration of ongoing jobs or used strategies based on inferring job durations from retention rates calculated from short panels or synthetic cohort data. In many ways available data on job durations resembles data that was available for research on unemployment duration in the 1980s.

In this paper we use administrative data from the Finnish pension insurance companies. These data cover a time period starting from 1963, the year following the creation of the current earnings related pension system in 1962, up to the recent pension reform in the end of 2004. We have access to a representative sample of fifteen cohorts of Finns who were employed in the private sector at some point during this 42 -year interval. The oldest cohort was born in 1905 and the youngest cohort in 1975. The data include the starting and ending dates of all insured employment spells of all individuals in the sample. This allows us to create a sample of job spells that were ongoing in January $1^{\text {st }}$, 1963 or started sometime after that date and follow these spells until they end - even if 
the jobs last for several decades. For some cohorts this implies that we can observe all employment spells during the entire career and directly observe the completed durations of all employment spells.

We start by taking snapshots of data at regular intervals and by computing the distribution of the elapsed duration of ongoing jobs at various points in time. Since we are using administrative data, many problems related to recall errors and consistency of measurement over time can be avoided. Also problems due to non-response or panel attrition do not arise with administrative records. To verify that administrative data is consistent with typical survey data, we compare the results from administrative records to the data on tenure distribution in the Labor Force Survey. In Finland this can be done starting from 1982. We then proceed to the analysis of differences in elapsed tenure at a given age between successive cohorts. Though this approach is commonly used in analysing changes in job stability, we would argue that it is not a particularly appealing way of analysing the changes in job stability. To demonstrate this, we simulate the effects of changes in the entry rate of new jobs and the hazard of job ending this on commonly used measure for job stability.

Since we have access to genuine panel data that for some cohorts cover the entire careers we can directly model the changes in the hazard of job ending. We do this using a competing risks model and analyse separately exits to other jobs and exits to nonemployment. We are primarily interested in the variation of these hazards over time but also account for the effects of elapsed duration, age and gender on the hazard of job ending. 


\section{Data}

Our data are based on individual pension contribution records of workers covered by the Employee Pension Insurance Scheme. Data were originally collected for calculating pension accruals.

The Finnish pension system is a defined-benefit system where each employment spell contributes to the old-age pension with a fixed accrual rate multiplied by the duration of the employment spell. Current system was created in 1962 and reformed in 2005. Pension contributions are mandatory and employers are liable for arranging pension insurance for all their employees. The system is operated by private insurance companies. When the workers retire the full pension is paid by the insurance company that had insured the last employment spell. The Finnish Centre for Pensions supervises the system and acts as a clearinghouse that allocates pension liabilities to the companies that received the pension contributions and transfers the funds to the company that will pay the pension to the retiree.

To perform its task the Finnish Centre for Pensions has access to full pension contribution records of all pension insurance companies. Importantly for this study, these records include information on the starting and ending dates of all employment spells. The data set that is used for this study was created at the Finnish Centre for Pensions for developing indices that are used in converting the pension accruals to the price level prevailing at the time when the employees retire.

The sampling frame includes all individuals who have contributed to the pension system between 1963 and 2004. The sampling was done using a stratified design first selecting those born on the eighth day of each month from every fifth cohort born between 1905 and 1975. Within each cohort individuals were then picked at random until a desired sample size was reached. For the individuals that are selected into the sample all employment spells between 1963 and 2004 are included in the data. Data contain cohort-specific sampling weights that are used throughout the paper.

In the Finnish pension system employment spells contributed to the pensions from age 23 onwards. This age limit was reduced to 18 in 2005. For this reason the data from the 
earlier years only contain employment spells from age 23 onwards. For the last three cohorts employment spells are recorded from age 18 onwards. However, data contain the starting date of the employment spell also for the spells that were ongoing on the $23^{\text {rd }}$, and for the last cohorts, on the $18^{\text {th }}$ birthday.

The first observations in the data are from 1963. Also in this case the data contain starting dates of all employment spells that were ongoing on January $1^{\text {st }} 1963$ no matter when the job had started. Therefore, the sample is representative of all ongoing employment spells between 1963 and 2004 for the cohorts that are included in the sample. Naturally the follow-up period varies between cohorts. The oldest cohorts are only observed at the end of their careers and the youngest cohorts only at the beginning of their careers. The 1940 birth cohort is the only cohort that is observed from age 23 to age 64. The age range when each cohort is observed and the sample sizes available for each cohort are displayed in Table 1.

TABLE 1 The observation period for each cohort in the original data set

\begin{tabular}{ccccc}
\hline \multirow{2}{*}{ Birth cohort } & \multirow{2}{*}{$\begin{array}{c}\text { Years when } \\
\text { observed }\end{array}$} & \multirow{2}{*}{$\begin{array}{c}\text { Ages when } \\
\text { observed }\end{array}$} & \multicolumn{2}{c}{ Sample size } \\
\cline { 5 - 6 } & & $58-64$ & 283 & 324 \\
1905 & $1963-1970$ & $53-64$ & 295 & 422 \\
1910 & $1963-1975$ & $48-64$ & 296 & 510 \\
1915 & $1963-1980$ & $43-64$ & 331 & 658 \\
1920 & $1963-1985$ & $38-64$ & 401 & 1,082 \\
1925 & $1963-1990$ & $33-64$ & 442 & 1,593 \\
1930 & $1963-1995$ & $28-64$ & 469 & 2,863 \\
1935 & $1963-2000$ & $23-64$ & 456 & 2,878 \\
1940 & $1963-2004$ & $23-59$ & 494 & 4,569 \\
1945 & $1968-2004$ & $23-54$ & 514 & 4,955 \\
1950 & $1973-2004$ & $23-49$ & 538 & 4,563 \\
1955 & $1978-2004$ & $23-44$ & 533 & 5,890 \\
1960 & $1983-2004$ & $18-39$ & 1,022 & 13,094 \\
1965 & $1983-2004$ & $18-33$ & 1,020 & 13,009 \\
1970 & $1988-2004$ & $18-29$ & 975 & 10,223 \\
1975 & $1993-2004$ & & & \\
\hline
\end{tabular}

The main limitations of the data are due to changes in the pension coverage over time. First, as already noted, the cohorts born before 1965 are only included in the data from 
their $23^{\text {rd }}$ birthday. To keep the data consistent across cohorts, we have excluded all job spells ending before age 23 also for the younger cohorts. Second, the data excludes very short spells lasting for less than one month because these jobs were not insured under the Employees’ Pension Scheme (TEL). Before 1965 this limit was six months and between 1965 and 1971 four months. We have no data from jobs insured under Temporary Employees' Pension Act (LEL) that cover the employees in construction, agriculture, forestry and harbour work. The main reason for this is that LEL-insurance is based on monthly gross earnings and has no need to record employment dates.

Finally, the data covers both public and private sector workers but the coverage of the public sector is incomplete before the 1980s. To minimize the effect of changes in insurance coverage, we exclude all public sector employment spells from most empirical calculations. In the empirical analysis we also exclude self-employed and farmers (both covered by their own pension schemes) and hence focus on the private sector employees covered by Employees Pension Scheme (TEL) for which we have information reported in a consistent way for the whole 42-year-period. Our analysis sample covers most private sector workers. For example, in 2004 about 90 per cent of private sector employees paid contributions to the Employees Pension Scheme.

In addition to dates of job spells the data contain only a limited amount of other information. Age and gender can be inferred from the id-codes. Reasons why job spells ended can be used to identify those who retire, but not to distinguish between dismissals and quits. As a partial solution we can classify jobs endings as quits and layoffs based on whether the employee started a new job within two weeks after the end of the previous job.

Other than removing the public sector employees, we have made only minimal adjustments to the original data. We removed short overlapping job spells in cases when a short spell begins and ends while a longer spell is ongoing. Job spells that are ongoing on December $31^{\text {st }}, 2004$ or ongoing on the day when the worker turns 65 are marked as censored. Jobs that were ongoing in January 1963 are also included in data and coded according to their original starting date. Data are left-truncated since we can only observe spells that lasted until 1963. Left-truncation also arises because spells that end 
before the $23^{\text {rd }}$ birthday as well as spells lasting for less than 6 months before 1965, less than 4 months before 1972 and less than one month thereafter are not observed.

\section{Comparison to other data sources}

Most commonly studies on job stability are based on consecutive cross-sectional surveys that have been widely available for research purposes. Several studies in the United States have used data from the Current Population Survey (CPS). It collects information on tenure with the current employer or in the current job in various mobility supplements conducted at irregular intervals since 1951.

Comparable cross-sectional survey data have also been used in several other countries to measure the changes in job stability. Heisz $(1999,2005)$ used monthly tenure data collected in the Canadian Labor Force Survey (CLFS) since 1976, Gregg and Wadsworth (1995, 2002) and Burgess and Rees (1996, 1997, 1998) used data from the British Labor Force Survey (BLFS) and data from the General Household Survey (GHS). Both data sets include annual information on the current tenure of the respondents since 1975 and 1974, respectively. Vejsiu (2001) used data from the Swedish Level of Living Surveys and the Swedish Labor Force Survey. These two data sources contain information on the current tenure in ongoing jobs in Sweden from 1968 onwards. The Swiss Labor Force Survey used by Sousa-Poza (2004) has gathered information on the current tenure of the respondents since 1991.

While independent cross-sectional surveys are designed to be representative for the target population in each cross-section, the fact that they lack information on eventual tenure after the interview date is unfortunate. CPS income supplements offer a slight improvement making it possible to follow respondents in two consecutive years (Stewart 2002). Similar two year panel has been available in the aforementioned Swiss Labor Force Survey. Nevertheless, the main approach employed in studies using CPS data and comparable sources from other countries has been to analyze the changes in the current tenure distribution (Farber 1995, 1997, 2007; Jaeger \& Stevens 2000) or to rely on strong assumptions that allow predicting future retention rates (Swinnerton \& Wial 
1995; Diepod, Neumark \& Polsky 1997; Neumark, Polsky \& Hansen 2000;) or eventual competed duration of the job held by the respondents (Hall 1982; Ureta 1992).

Several studies have employed panel data to analyze the changes in job stability. In the United States, Marcotte (1999), Polsky (1999), Gottschalk and Moffit (2000) and Jaeger and Stevens (2000) all use the Panel Study of Income Dynamics (PSID). Since 1976, the PSID has included a question on the current tenure, and in principle the annual interviews allow one to track employment histories of the survey respondents.

Other panel data sets used in US studies on job stability include the Survey of Income and Program Participation (SIPP) and the National Longitudinal Surveys (NLS). The SIPP data used by Gottschalk and Moffit (2000) and Bansak and Raphael (2006) include information on the job histories of the individuals typically over a period lasting 32 months. The National Longitudinal Survey of Young Men and the National Longitudinal Survey of Youth, have been used for analyzing job stability by Bernhardt, Morris, Handcock and Scott (2000). These two data sets provide the researchers with a 16-year follow-up of the employment histories of young men starting from a cohort born in 1944, and include employer coding that captures job changes.

The German Socio-Economic Panel (GSOEP) was used by Winkelmann and Zimmermann (1998) and Bergemann and Mertens (2004). These data are available since 1984 and include information on both the current tenure of the individuals and their labor market transitions between consecutive interviews. In addition, when the GSOEP was initiated in 1984, the respondents were asked about the number of employers they had during the past 10 years. Even longer retrospective data is available in Britain. Booth, Francesconi and Garcia-Serrano (1999) use retrospective employment history data gathered in 1993 as a part of the British Household Panel Survey (BHPS). This survey asked the respondents to list their employment history until September 1990 starting from the day they left full-time education.

Naturally, the risk in using retrospective data for analyzing changes in job stability is that the respondents may not recall short employment spells in distant past which could lead to a false impression of declining job stability. A perhaps better alternative is to compare retrospective information in surveys conducted at different times. This 
approach was applied by Stevens (2005) who used data from the Retirement History Survey (RHS), the National Longitudinal Survey of Older Men (NLSOM) and the Health and Retirement Survey (HRS) to measure changes in the distribution of the longest job held by the respondents during their career.

Data from administrative registers has been used only recently for analyzing changes in job stability. For example, Bratberg, Salvanes and Vaage (2006) use linked employeremployee data from the period 1986-2002 to investigate the changes in job stability in Norway. Also Mahringer (2005a, 2005b) uses administrative employment spell data based on the Austrian social security records from 1975 onwards. These data sets, along with the pension register data employed in this paper, can be seen as considerable improvements to the job stability literature by making it relatively easy to follow job spells over time and by avoiding several problems researchers have previously faced with survey-based data. 


\section{Descriptive analysis}

\section{Changes in average tenure over time}

As a first attempt to describe changes in job stability in our pension records data we examine the changes in the average tenure over time. We pick an arbitrary date, October $15^{\text {th }}$, each year and report the average elapsed duration of the jobs that were ongoing on that day. The results are plotted in Figure 1. We report both simple averages and regression adjusted averages that account for changes in the age and gender distribution. The horizontal line in the figure refers to the overall arithmetic average, 8.7 years.

The unadjusted numbers are trending slightly upwards over time. This partly reflects population aging. Older workers have accumulated on average longer tenure, and an increase in their share in the data increases the average tenure. It is not clear whether any adjustments for population aging should be made; an increase in average tenure is a real phenomenon even if it is caused by a change in the age structure. However, our sample is not exactly representative of the current population in any single year; it is only representative for the certain cohorts. Since a new cohort is added to data every fifth year, the sample gets successively older for five years and then suddenly younger as a new cohort enters in the data. The effect of sampling scheme can be seen as a modest five-year cycle in the unadjusted average tenure. The age effect is particularly strong in the end of the data. The youngest cohort born in 1975 is included in the data in 1998, but after that no new cohorts enter and the sample gets gradually older.

The largest changes in the adjusted average tenure series occur in the end of 1970s when the average tenure increases and in the 1990s when average tenure starts a gradual decline. 


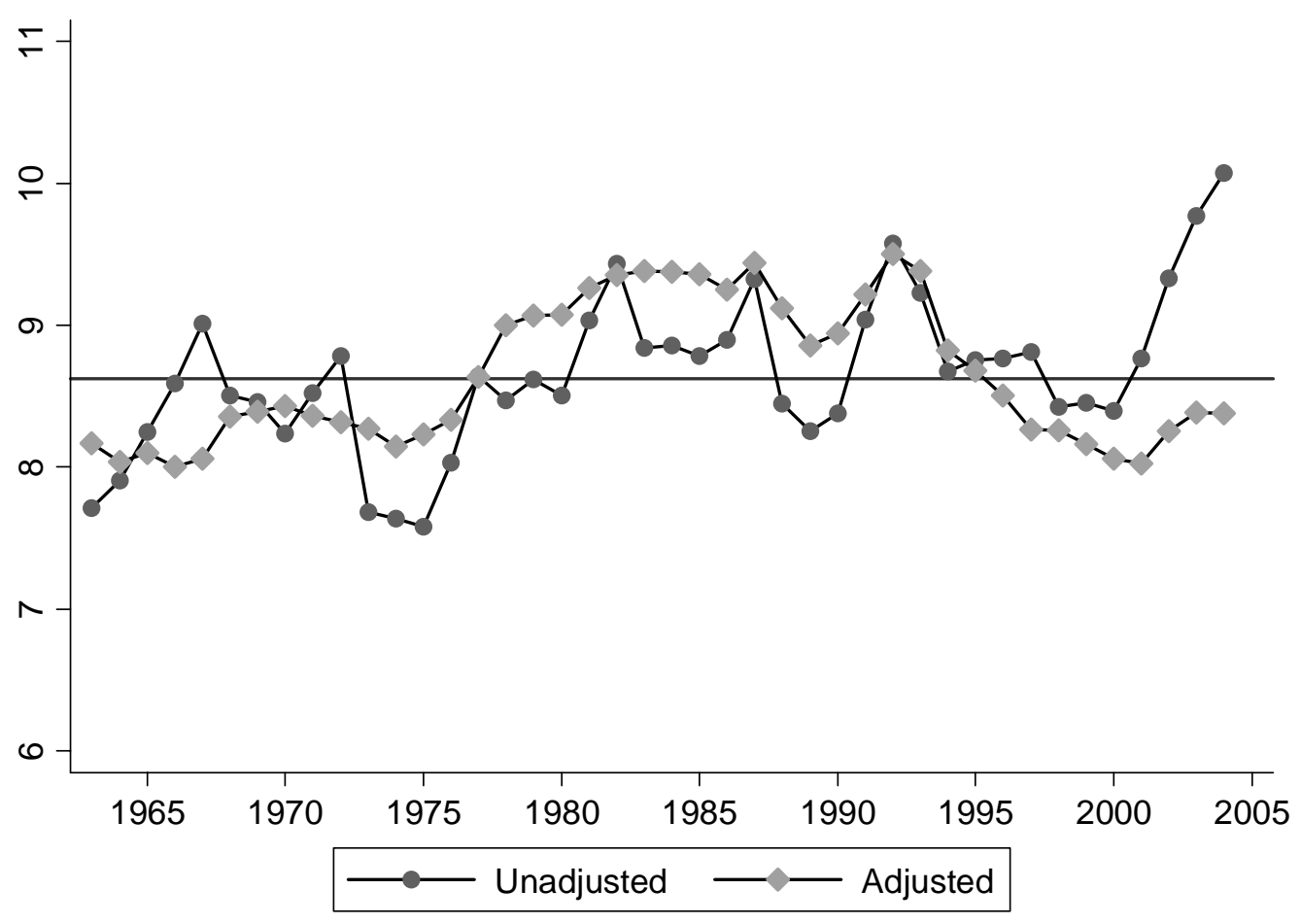

Figure 1 Average tenure in current job 1963 - 2004

Note: Adjusted series is created by regressing elapsed duration on gender and one-year age dummies and calculating the predicted values when gender and age distributions are set equal to the sample average.

\section{Comparison of register vs. survey data}

To verify that changes occurring in the register data are not due to changes in reporting procedures or changes in insurance coverage, we compared the tenure distribution in the register data to the figures calculated from the Labor Force Survey².

\footnotetext{
${ }^{2}$ Questions on the current tenure were first added to the annual interview of the Labor Force Survey in the fall of 1982. The question on current tenure was included in the survey every year until 1987 and then and every other year between and 1987 and 1993. In 1995 and 1996, the tenure question was included in the EU Labor Force Survey conducted in spring. From 1997 onwards the question on elapsed tenure has been included in the monthly Labor Force Survey. In addition to changes in survey dates, also the survey question has been changed slightly which may make the LFS time-series less consistent over time.
} 
Comprehensive micro-level data from the Labor Force Survey are not available for research purposes in Finland. Therefore, we cannot calculate simple statistics such as the mean tenure for years before 1997. However, Statistics Finland regularly publishes monthly data on new jobs, defined as jobs with tenure less than a year. Statistics Finland also provided us with unpublished tabulations on the tenure distribution that allow calculating the fraction of jobs with current tenure of more than ten years in a consistent way.

In Figure 2 we plot the fraction of workers with elapsed tenure over one year and in Figure 3 fraction of workers with elapsed tenure over ten years based on both the pension records and on the survey data. We have made the sources as comparable as possible. Since the annual interview of the LFS was held between September and December in the 1980s we use data from the last quarter of the year also after 1997. After 1980s the coverage of the register data is better so that, in contrast to the other analyses in this paper, also the public sector employees and workers under 23 can be included in this comparison.

According to Figures 2 and 3 the evolution of the tenure distribution is very similar in the survey and register data. According to both sources, on average, about $80 \%$ of the workers have been in their jobs for more than a year. Also the changes in tenure distribution seem similar. According to both sources there was a large increase in the fraction of workers with more than one year of tenure in the beginning of 1990s. This does not imply that job markets were more stable during those years, rather the opposite. Finland experienced a major recession in the beginning of 1990s and very few workers were recruited during those years. Hence the fraction of new workers with short tenure declined and average tenure increased.

Survey and register data seem to produce similar numbers also in Figure 3 that displays the fraction of workers with more than ten years of tenure. According to either source about 35 to $40 \%$ of workers have been working for their current employer for more than ten years. There is also a slight increase over time, again potentially explained by population aging. 


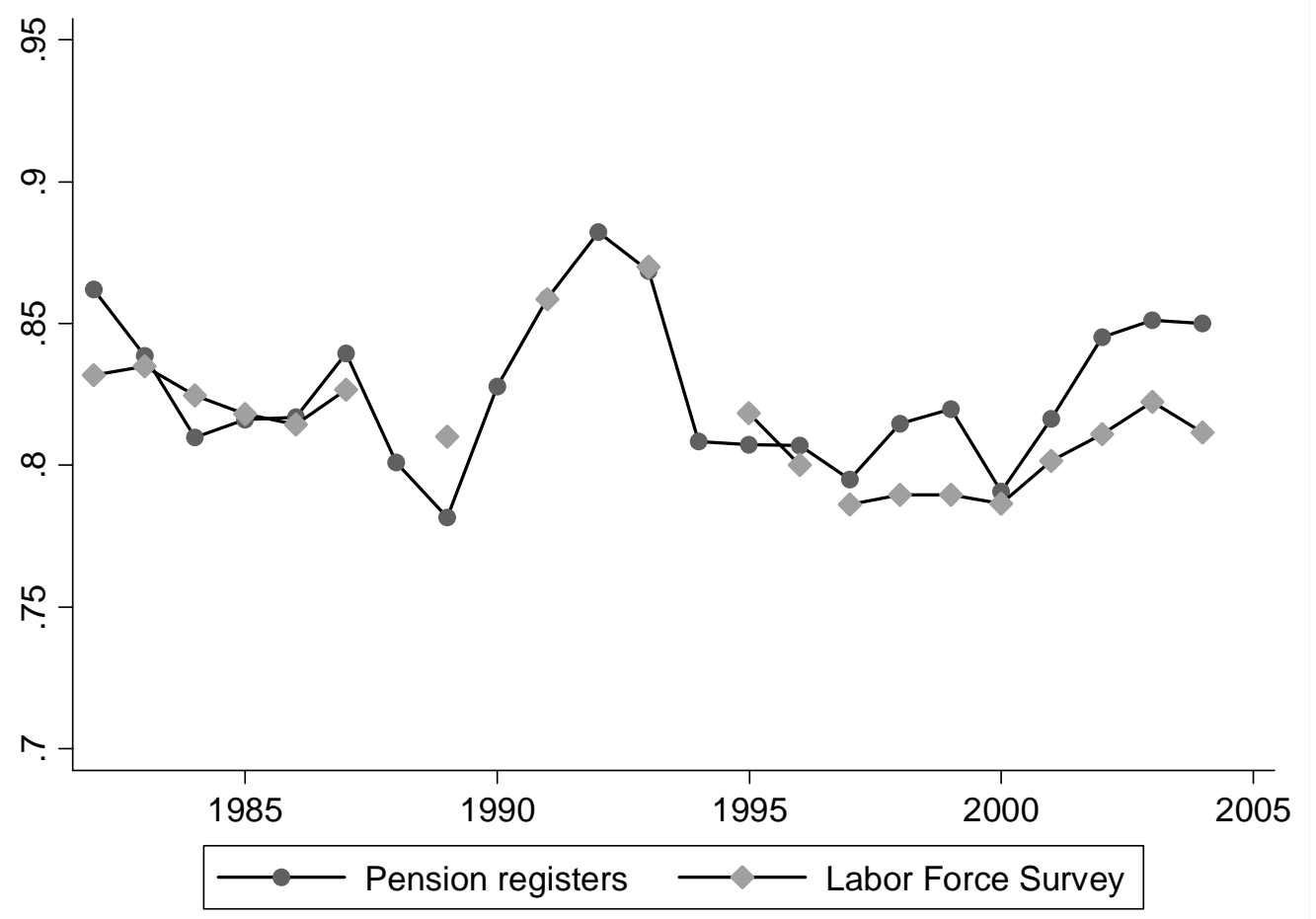

Figure 2 Share of workers with elapsed tenure $>1$ year in register vs. survey data

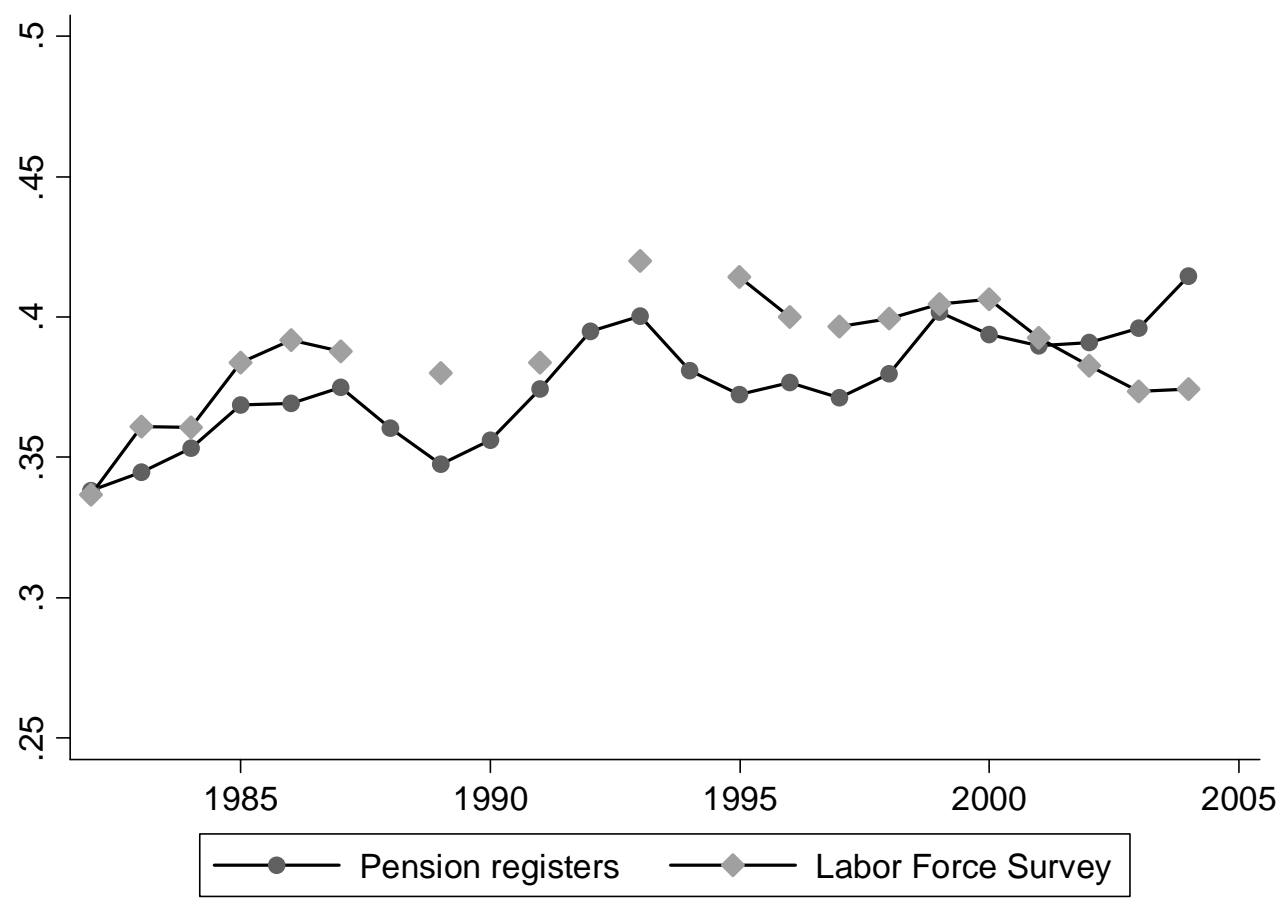

Figure 3 Share of workers with elapsed tenure $>10$ years in register vs. survey data 
Notes to Figures 2 and 3:

Elapsed tenure in register data is calculated based on jobs ongoing on October $15^{\text {th }}$ each year. Data includes workers between 18 and 64 and cover both public and private sector employees. Self-employed are excluded. Survey data up to 1993 is based on annual interview of the Labor Force Survey. Data from 1995 and 1996 are from EU Labor Force Survey. From 1997 onwards data is based on monthly Labor Force Survey. To avoid inconsistencies due to differences in survey dates we have used the numbers from the last quarter of each year.

\section{Differences across cohorts}

Examining changes in current tenure in a given year may not be the best way to capture long-term changes in job stability. Possibly a better approach is to compare differences in elapsed tenure at a given age between consecutive birth cohorts.

In Figures 4a and 4b we follow the example by Farber (2007) and plot average elapsed tenure by age for different cohorts separately for men and women. For clarity we aggregate the cohort data slightly and take an average of three consecutive cohorts so that the first line refers to cohorts born between 1905 and 1915 and the last line to cohorts born between 1965 and 1975.

According to Figures 4a and 4b the average elapsed tenure increases almost linearly by age. The increase is more rapid for men. At age 50 the average tenure for men is about 15 years and average tenure for females about 12 years. Differences across cohorts are not very large except in the older ages where also the number of observations gets small and the estimates less precise. Still, one can note that the youngest cohorts born between 1965 and 1975 have accumulated slightly less tenure at any given age than the cohorts born before 1965 . 


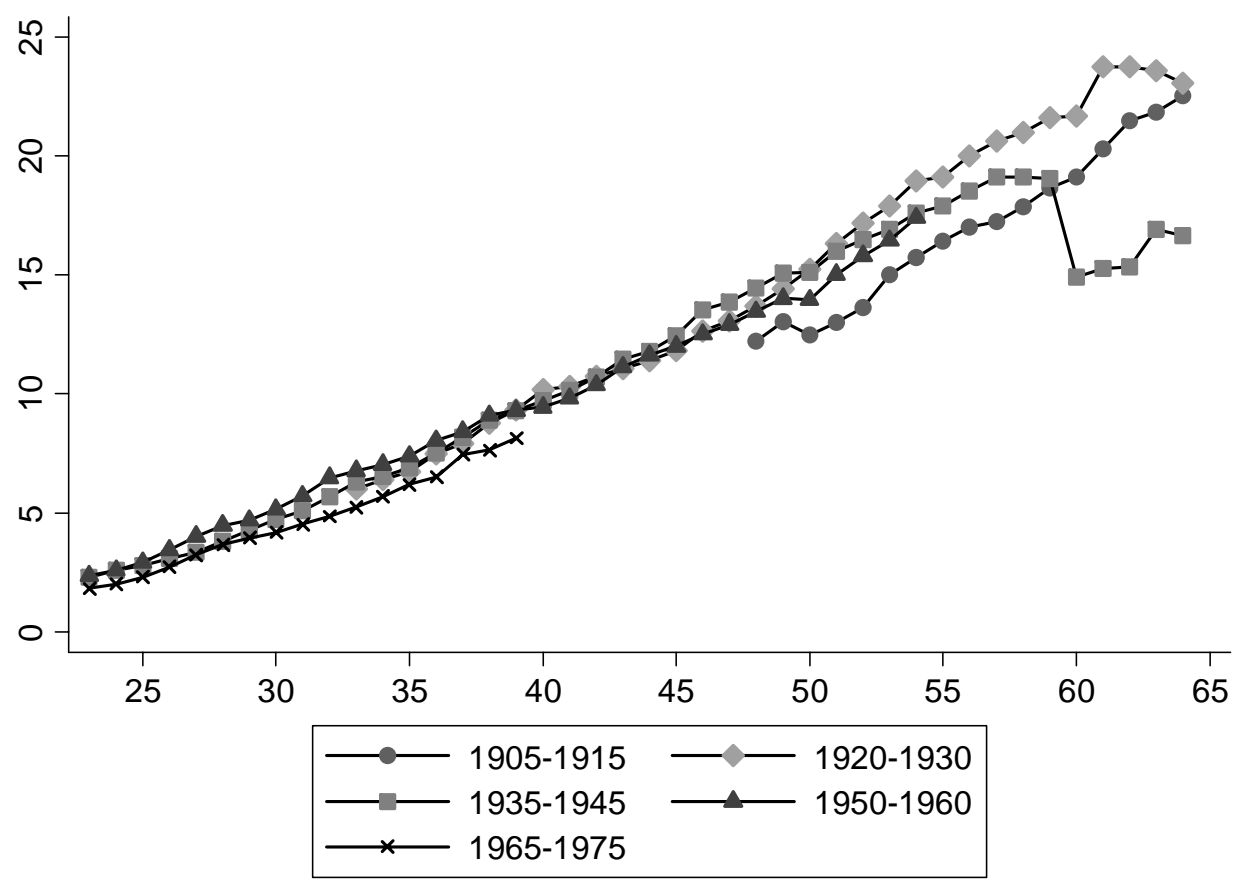

Figure 4a Mean elapsed tenure by age and cohort, men

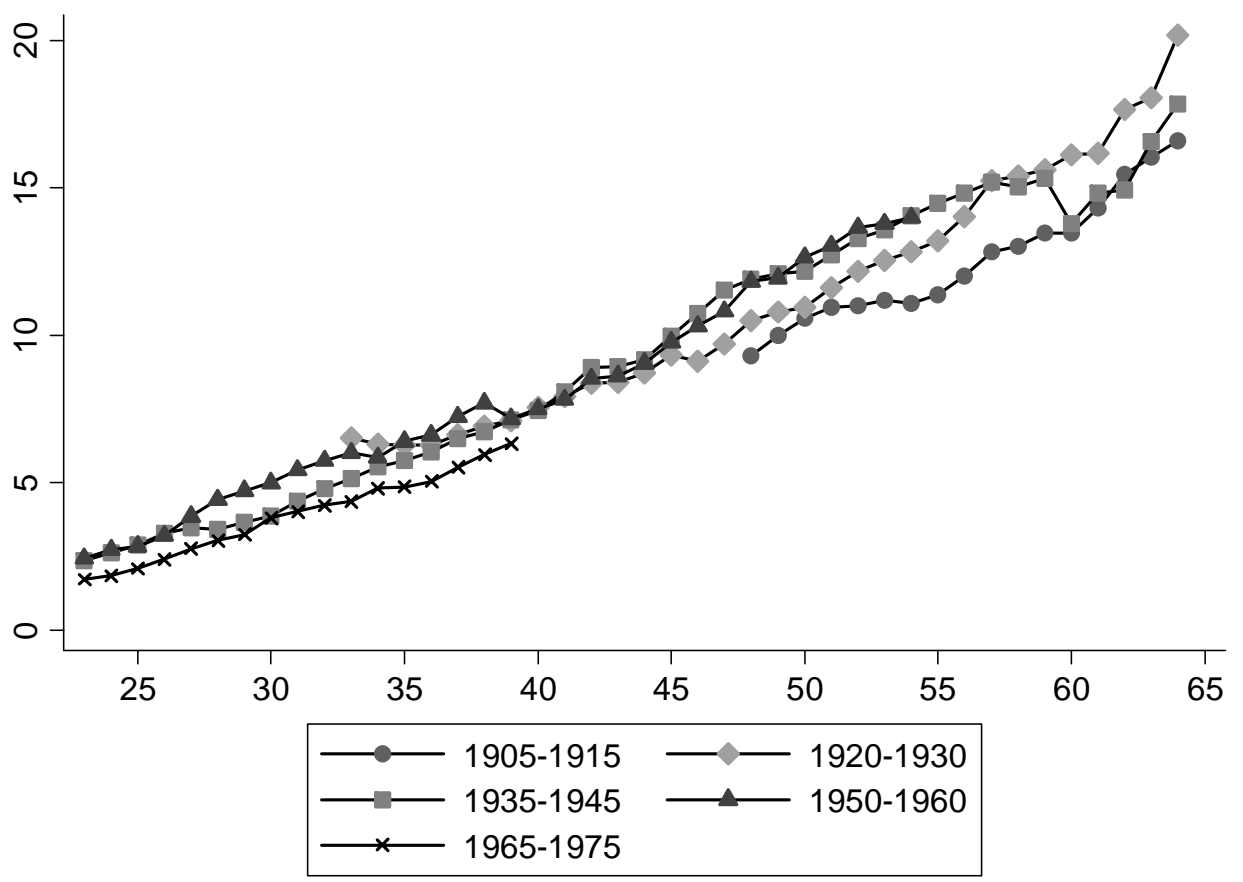

Figure $4 b$ Mean elapsed tenure by age and cohort, women 
The differences across cohorts can be seen more clearly from Figure 5 that presents the cohort effects from a regression model where (log) current tenure is explained by a set of cohort dummies and a full set of one-year age dummies. The figure shows that, conditional on age, average tenure was lower in the first female cohorts but then remained rather stable for both men and women until the cohorts born in 1950s. For both men and women age adjusted average elapsed tenure is smallest among the youngest cohorts.

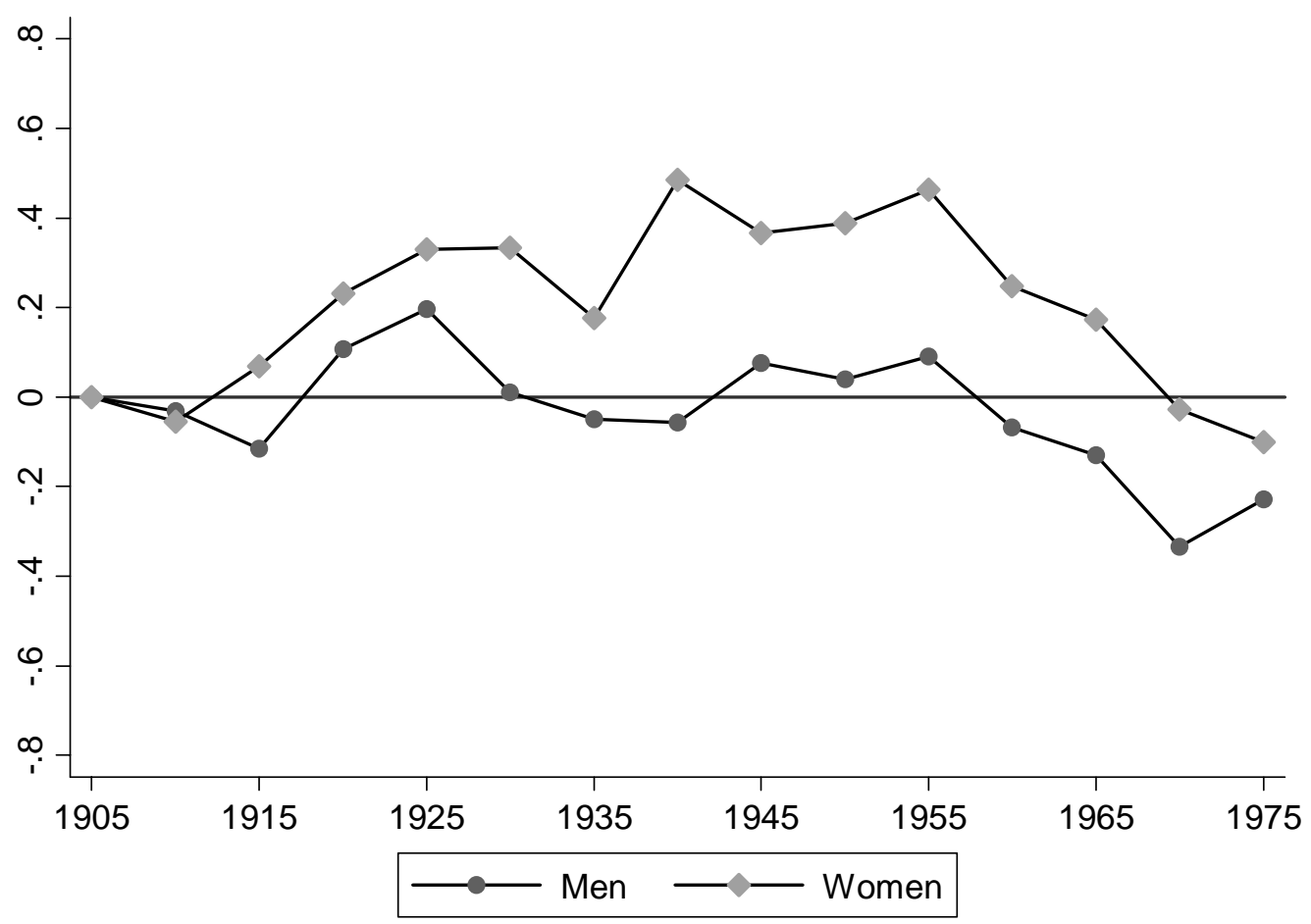

Figure 5 Cohort effects on current tenure

It should be noted that the decrease in the average age-adjusted tenure does not necessarily imply that the jobs held by the youngest cohorts would be less stable but also reflects a delay in the age of entry into the labor market due to an increase in time 
spent in education. Figure 6 displays the labor force participation rate and the employment rate in age group between 15 and 24. Both fluctuate according to the business cycle but have also declined substantially over time. The labor force participation rate in this age group is about ten percentage points lower and the employment rate about twenty percentage points lower in 2004 than in 1970.

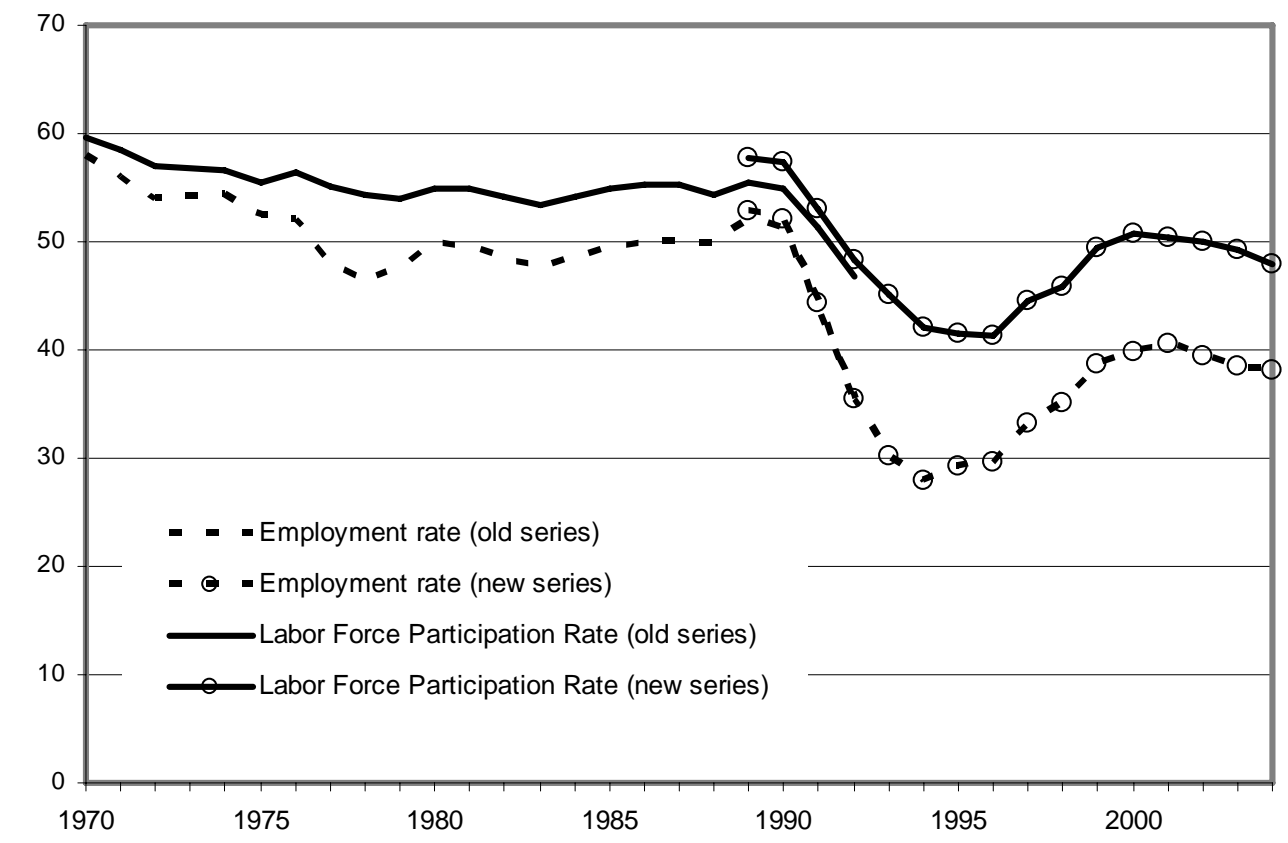

Figure 6 Labor force participation rate and employment rate in ages 15-24

Data source: Labor Force Survey, Statistics Finland database. Break in series is due to the reform in the Survey. 


\section{Effects of the changes in entry rates and the risk of job loss on average tenure}

Though commonly used, the change in mean elapsed duration of ongoing employment spells may not be a particularly informative statistic for measuring the changes in job stability. To illustrate this we simulate the dynamic effects of changes in job stability defined as the change in the risk of job ending on average tenure.

We follow Lancaster (1990) and start by noting that the number of persons employed at time $t_{0}$ is

$$
\int_{0}^{\infty} n(-y) S_{-y}(y) d y,
$$

which depends on the number of entrants $y$ periods ago $n(-y)$ and their historical $y$ period survival rates $S_{-y}(y)$. Hence, the mean elapsed duration of ongoing spells at time $t_{0}$ is

$$
\mu_{t}=\frac{\int_{0}^{\infty} n(-y) S_{-y}(y) y d y}{\int_{0}^{\infty} n(-y) S_{-y}(y) d y} .
$$

In general, the expression (2) depends on all past entry rates and all past survival rates. For example Ureta (1992) notes that calculating average completed tenure based on survival rates calculated from a cross-section data as was done in the famous paper by Hall (1982) leads to a bias if the arrival rates are not constant. Ureta's example of nonconstant arrival rates had to do with increased labor force participation rates by women. Similar effects could be caused by large scale changes in immigration, changes in school-leaving age or major swings in the business cycle.

However, even if the entry rates were constant, the mean elapsed duration of ongoing jobs depends on all past survival rates and not only on the recent changes that a measure of changes in job stability should capture. Hence, for example a major recession that causes a temporary shock to the job exit rates affects average tenure long after the recession has ended. 
In Figure 7a we illustrate the effect of an increase in the labor market entry rate on the average duration of ongoing jobs. We start from a stationary state where the number of new entrants is constant and equals the labor market exit rate. We estimate a KaplanMeyer survival function from our pension record data and use expression 5 to calculate average duration of ongoing jobs. To simplify calculations, we assume that there is no unemployment so that the workers whose contracts end immediately find a new job where their tenure is naturally initially zero.

We then increase the entry rate with a constant number of new entrants each year so that total employment increases by 20 per cent in 20 years and remains constant thereafter. We use equation (5) to calculate average tenure in ongoing jobs each year from $t=0$ to $t=100$. According to the results presented in Figure $7 \mathrm{a}$ the increase in labor market entry decreases the average tenure because there are more recent entrants with short tenure. Interestingly the effect of an increase in the entry rate has a long-lasting effect. Even at time $t=30$ the average tenure is substantially below the initial level even though the increase in the entry rate had ceased ten years ago. The average tenure stabilizes to the initial level after about forty years.

A researcher comparing average tenure generated by our simulation between, for example, years $t=0$ and $t=30$ might well conclude that average tenure has declined and jobs become less stable. The conclusion would be quite misleading. The survival function of new jobs, and hence the average eventual completed tenure, is constant in our simulations. The decrease in average elapsed tenure in a cross-section is entirely due to an increase in the number of recent entrants. 


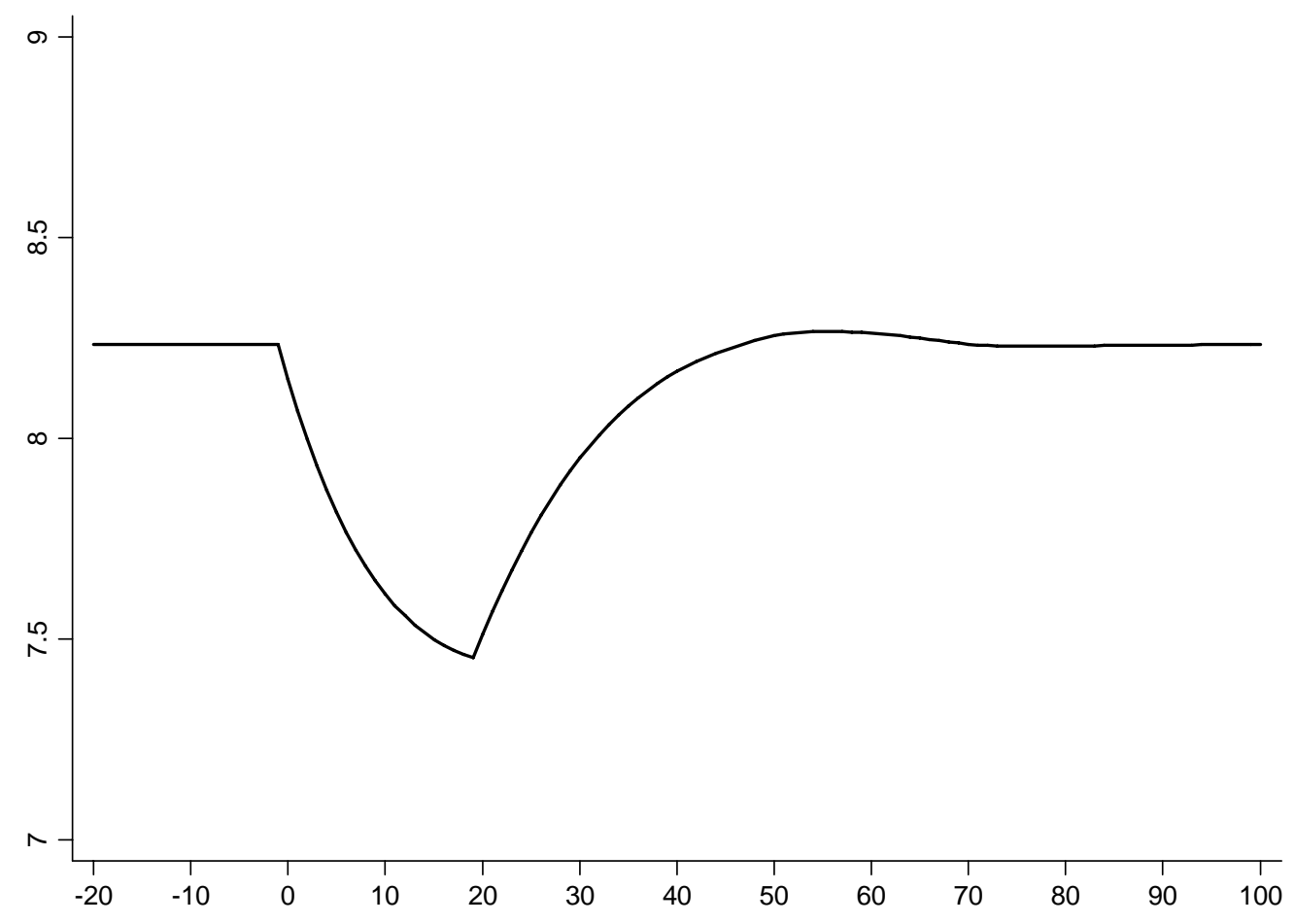

Fig 7a Simulation results: Effect of an increase in entry rate on average tenure

In Figure 7b we present results from another simulation more closely related to changes in job stability. We keep the number of new entrants constant but simulate the effects of a temporary increase in the hazard of job ending. We start again with survival function estimated from our pension records data but increase the hazard of job loss by 50 percent for five years for all cohorts that are in the labor market between years $t=0$ and $t=5$. After five years we return the hazard rate to its initial level. Average elapsed tenure is again calculated based on equation (5) for time periods from $t=0$ to $t=100$.

As shown in Figure 7b the increase in the hazard of job ending decreases the average tenure. Note that this is partly due to our simplifying assumption according to which the workers who lose their jobs are immediately re-employed (with zero tenure). This would also imply that hiring rate would have to increase. If an increase in the job ending rate led to an increase in unemployment, the change in average tenure would depend on 
the changes in re-employment rates. In a typical recession the re-employment rate decreases and leads to an increase in average tenure (Burgess and Rees 1996). The number of new (low tenure) jobs typically starts to increase only when recession is over. It is therefore better to interpret our simulation as an impact of temporarily higher volatility rather than as an effect of recession.

The most interesting feature of simulation results presented in Figure $7 \mathrm{~b}$ is that a temporary increase in volatility has long-lasting effects on average tenure. Even though the shock to the job ending rates only lasts for five years the average tenure is substantially below the initial level several decades afterwards. Again data on the mean elapsed duration of ongoing jobs in consecutive cross-sections would give a misleading picture on the changes in uncertainty.

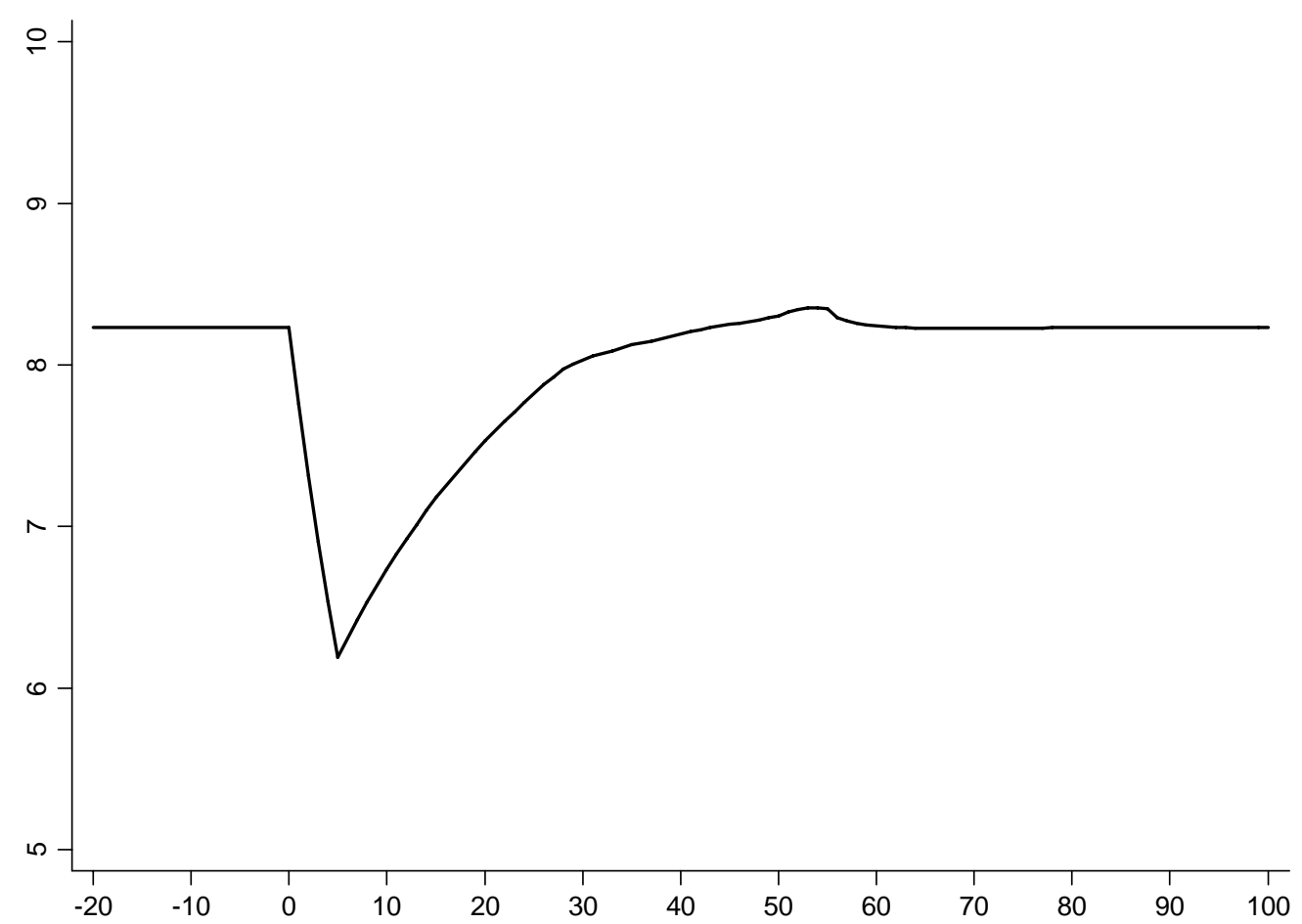

Fig 7b Simulation results: Effect of an increase in the hazard of job ending on average tenure 


\section{Changes in the risk of job loss - Results from a duration model}

The most natural measure of labor market uncertainty is probably the risk that a job ends. A standard way of modeling this risk is the conditional probability that a job ends given that it has lasted for a given time, i.e. the hazard rate. Modeling the effects of exogenous covariates on the hazard rate - instead of on e.g. the completed duration of a job - also provides a simple ways to account for censoring due to a finite observation period, duration dependence, and the effects of covariates that vary over time.

Our data is a sample of jobs ongoing on January $1^{\text {st }} 1963$ and of jobs beginning between 1963 and 2004. It is therefore a mixture of stock and flow samples. Jobs that began before 1963 are observed only if they are still ongoing in 1963 creating a left-truncated sample. Left truncation arises also because we observe only employment spells ongoing after the $23^{\text {rd }}$ birthday, and because jobs lasting less than 6 months until 1965, 4 months until 1972 and a month thereafter are not included in the data. The starting date is known also for the stock-sampled jobs. The ending dates of jobs that are still ongoing in the end of 2004 are unknown, and the data is hence right-censored at this point. We also censor jobs on the $65^{\text {th }}$ birthday as workers over 65 are no longer paying pension contributions and are thus not followed in the data.

To model the changes in the hazard of job ending we use a competing risks model with two possible destinations: non-employment and a new job. Our definition is based on whether we observe a new employment spell within two weeks after the previous spell ends. We also experimented with a time limit of four weeks for this definition, but this had practically no effect on the results.

A large number of jobs end soon after they begin. After a job has lasted for a year, the hazard of job loss declines to about a fifth of the hazard prevailing during the first four months. The decline in the hazard of job change decreases also though the decline is smaller. To allow flexible forms of duration dependence in both hazards we specify a piecewise constant baseline hazard function where the hazard stays constant for four month periods during the first year and for one year periods thereafter. 
We explain the changes in the hazard rates by gender, age and time. Again we aim to maximum flexibility and include the time varying covariates as a set of one-year age and time dummies. We assume that the covariates have proportional effects on the hazard rates. We also assume that there are no interactions so that, for example, duration dependence is independent of age. While these assumptions might be questioned, we would argue that they have little impact on our primary objective; consistent estimation of the time effects that capture the changes in the hazard of job ending over time.

We account for individual-specific unobserved heterogeneity by specifying a mixed proportional hazard model with three discrete points of support following the approach by Heckman \& Singer (1984). The choice of the number of support points is somewhat arbitrary, but experimentation with different numbers of discrete points revealed that the other parameter estimates remained practically unchanged with two, three, or four mass points . However, imposing a restriction that there is no unobserved heterogeneity would have substantial effects on the estimates.

We use the partial likelihood method (Lancaster 1979) that makes accounting for left truncation relatively easy. Jobs that are ongoing at the start of the observation period contribute to the hazard estimates only from the entry date onwards. The jobs that end within the observation period contribute to the likelihood function through both the hazard and the survival function, but the jobs that are still ongoing at the end of the observation period contribute only through the survival function.

Our model specification can be formalized as follows. We define the hazard function related to destination $s$ for job $j$ of individual $i$ conditional on the vectors of observed covariates $x_{i j}$ and individual-specific unobserved heterogeneity terms $v_{i}=\left(v_{i 1}, v_{i 2}\right)$ as

$$
h_{s}\left(t_{i j} \mid x_{i j}, v_{i}\right)=\lambda_{s}\left(t_{i j}\right) \exp \left(x_{i j}^{\prime} \beta_{s}+v_{i s}\right)
$$

We specify the baseline hazard function $\lambda_{s}\left(t_{i j}\right)$ for destination $s$ as

$$
\left.\lambda_{s}\left(t_{i j}\right)=\sum_{k=1}^{K} \lambda_{s k} I_{t_{i j} \in\left[d_{k-1}, d_{k}\right.}\right)
$$


where $I$ is an indicator function splitting each job spell into $K$ episodes.

Furthermore, the survival function related to destination $s$ for job $j$ of individual $i$ given the vectors of observed covariates $x_{i j}$ and individual-specific unobserved heterogeneity terms $v_{i}$ is defined as

$$
S_{s}\left(t_{i j} \mid x_{i j}, v_{i}\right)=\exp \left[-\int_{0}^{t_{i j}} h_{s}\left(u \mid x_{i j}, v_{i}\right) d u\right]
$$

Let $\theta$ denote the parameter vector to be estimated and $w_{i}$ the sampling weight of individual $i$. In addition, let $c_{i j s}$ denote a dummy variable indicating whether job $j$ of individual $i$ is censored. The pseudo log-likelihood function can now be written as

$$
\log L(\theta)=\sum_{i=1}^{N} w_{i} \log \left[\sum_{m=1}^{3} \pi_{m} \prod_{j=1}^{J_{i}} \prod_{s=1}^{2} \frac{h_{s}\left(t_{i j} \mid x_{i j}, v_{m}\right)^{1-c_{i j s}} S_{s}\left(t_{i j} \mid x_{i j}, v_{m}\right)}{S_{s}\left(e_{i j} \mid x_{i j}, v_{m}\right)}\right],
$$

where the term between the brackets is the marginal likelihood contribution of individual $i$. The parameters $v_{m}$ and $\pi_{m}$ denote the mass point vectors and corresponding probabilities of the unobserved heterogeneity distribution that are estimated along with the other parameters of the model.

We parametrize the probabilities $\pi_{m}$ of the unobserved heterogeneity distribution as

$$
\pi_{m}=\frac{\exp \left(p_{m}\right)}{\sum_{m^{\prime}=1}^{M} \exp \left(p_{m^{\prime}}\right)}
$$

and normalize $p_{1}$ to zero. This parametrization takes automatically care of the requirement that the estimated probabilities must lie between zero and one.

The role of the division by $S_{s}\left(e_{i j} \mid x_{i j}, v_{m}\right)$ in the pseudo log-likelihood function is to take into account the left truncation in our data. That is, we condition the likelihood 
contribution of each job on the fact that it must have survived until $e_{i j}$ which denotes the elapsed duration at which job $j$ of individual $i$ enters the data.

Our approach produces a large number of parameters. For expositional reasons we prefer presenting the estimated hazard ratios and their 95\% confidence intervals in a graphical way. The parameter estimates and their standard errors are reported in the appendix. We start by plotting the baseline hazard function in Figure 8a. We omit the first category with elapsed duration of 0-4 moths. As shown in the figure the hazard of job loss declines rapidly during the first few years. After having lasted for seven years the hazard is about 10 per cent of the hazard during the first four months. After that the hazard of job loss remains approximately constant for twenty years. The hazard of job change declines also, but the decline is clearly slower. At very high durations the estimates of job change hazard get less precise due to a small number of job changes.

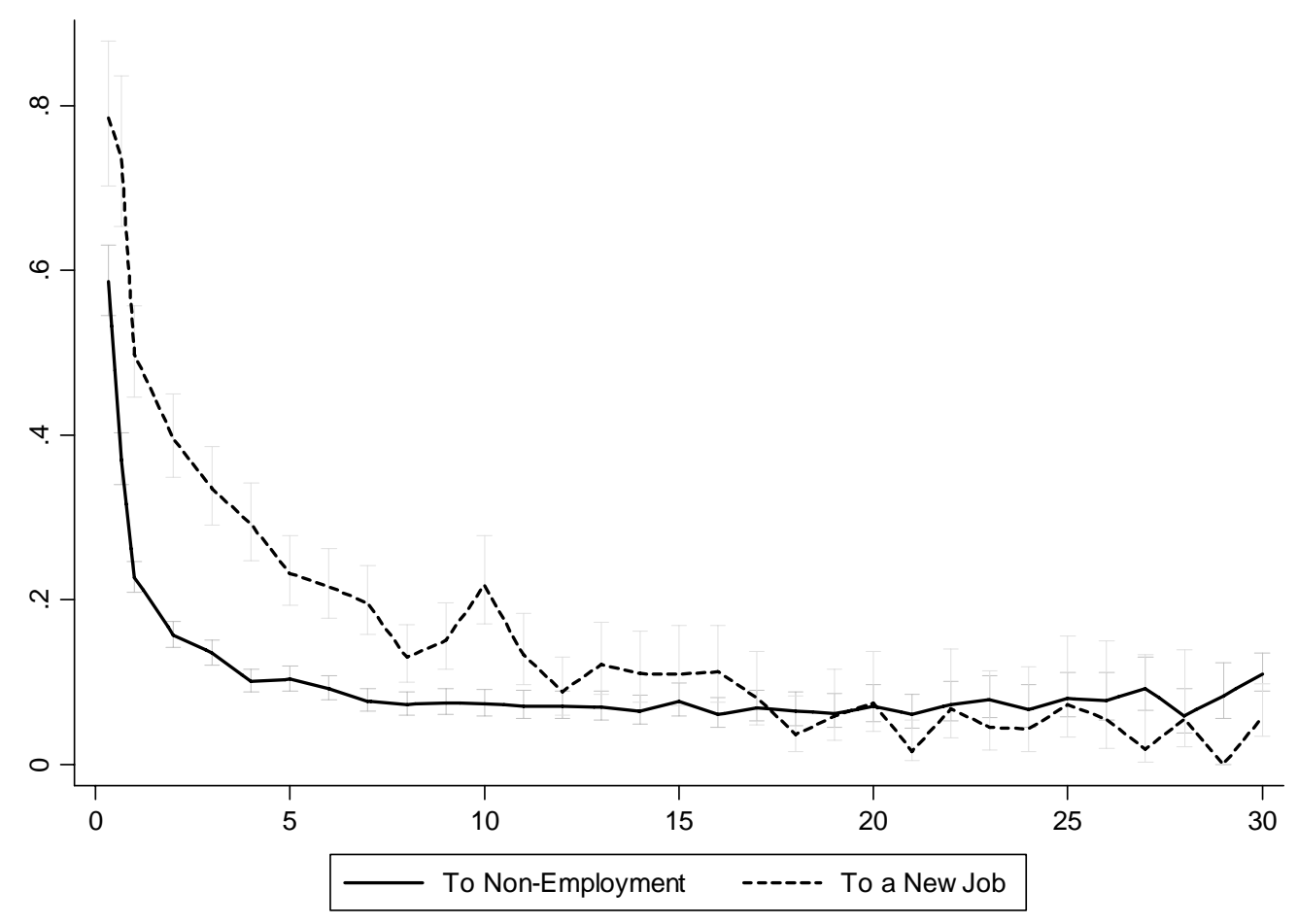

Figure 8a Hazard of job ending as a function of elapsed duration 
Figure $8 \mathrm{~b}$ presents the effect of age on the hazard rates. We have chosen age 23 as the reference category and omit ages 63 and 64 from the figure for expositional reasons. The risk of job loss first declines as the workers get older. From about age 52 onwards the hazard increases rapidly with age reflecting the effect of early retirement and gets very high after age 60 . Hazard of job change declines almost linearly as the workers get older.

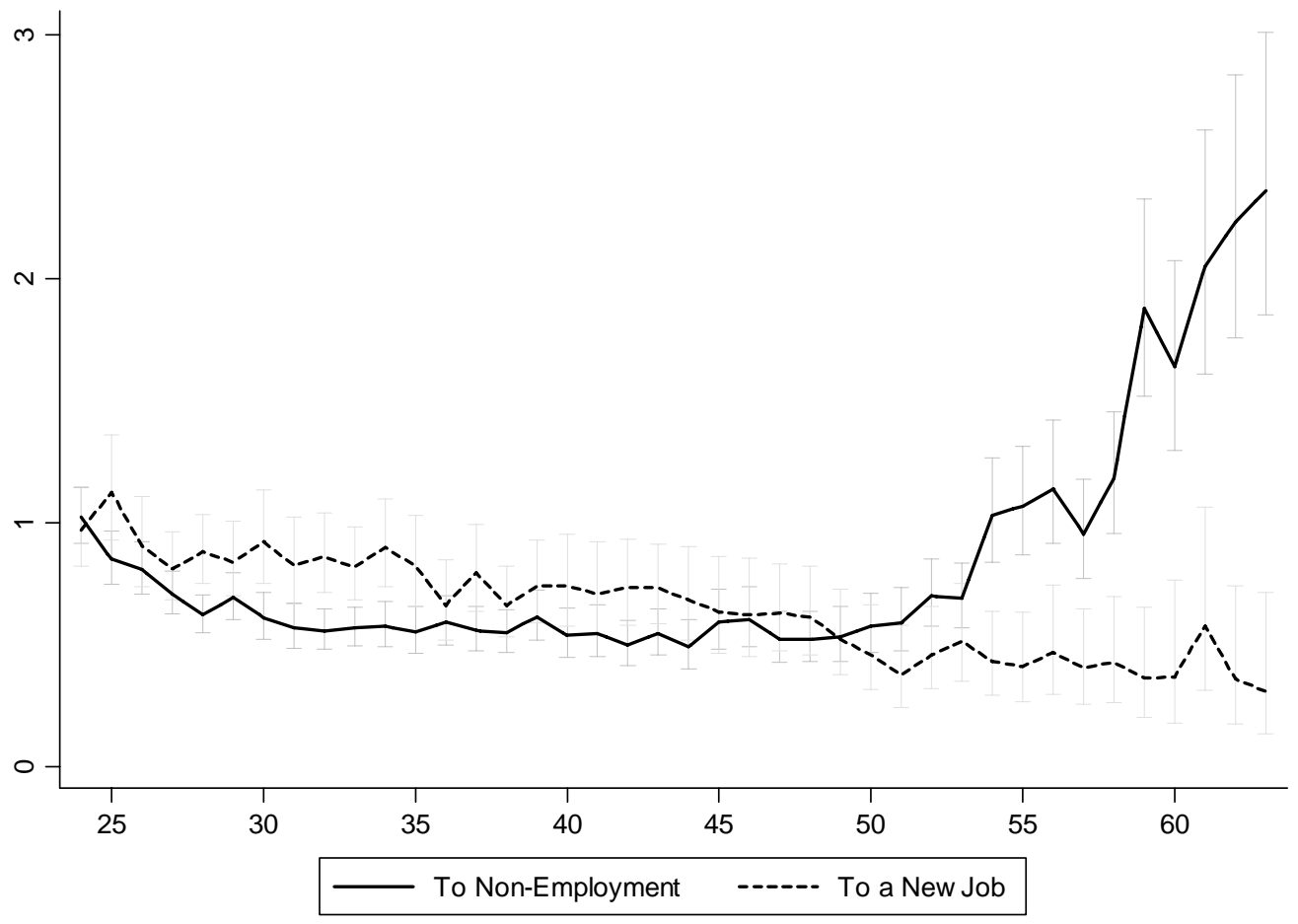

Figure $8 b$ The effect of age on the hazad of job loss

Finally in Figure 8c we plot the time effects using 1963 as a reference period. We find that the hazard of job change is much more volatile than the hazard of job loss. Early 1970s, late 1980s and late 1990s were years of particularly rapid job-to-job mobility. In contrast, there is only one peak in the hazard to non-employment that coincides with the recession in the early 1990s. If we interprete the hazard to non-employment as an indicator of uncertainty, we can also note that the uncertainty after year 2000 is approximately at the same level as it was forty years earlier, in the beginning of the 1960s. 


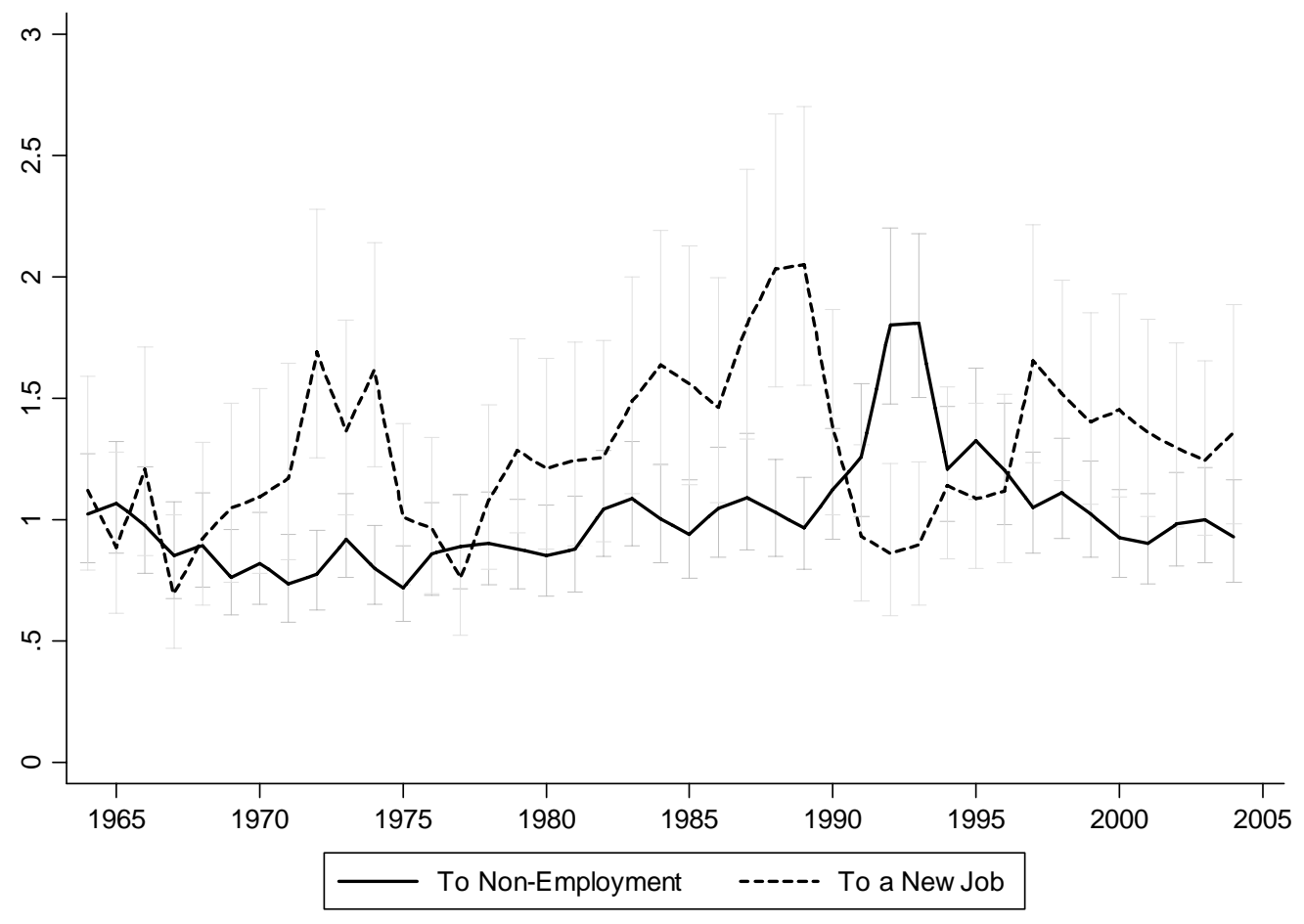

Figure 8c Time variation in the job termination hazard

A comparison of the job-to-job and job-to-non employment hazards to the mean elapsed duration of ongoing jobs presented in Figure 1 reveals that these series appear to be almost unrelated to each other. The increase in average tenure observed around 1980 could be partially explained by lower job-to-job mobility in the end of the 1970s and the decrease in average tenure after 1993 by an increase in job-to-job mobility in mid 1990s, but clearly something else is going on also. In addition, two possible measures of job security: mean elapsed duration of ongoing jobs and hazard of job ending point to very different time pattern in the changes of uncertainty prevailing in the labor market.

As we noted in the previous chapter, the mean elapsed duration of ongoing jobs depends not only on the current hazard of job ending, but also on past hazards and the variation in entry rates. To quantify these effects we used the estimates from a slightly simplified 
version of our duration model ${ }^{3}$ together with the number of new entrants each year and the initial duration distribution that prevailed in 1963 to simulate the average tenure in each year.

As shown in lower right corner of Figure 9 the simulated average tenure corresponds relatively well to the observed average tenure in any given year. Only major deviation between the observed and the simulated series occurs in the end of the series, and this can be explained by the changes in the age distribution of our sample. To quantify the effects of changes in job ending hazards on average tenure, we then restricted both the job-to-job and job-to-non employment hazards at their sample averages and simulated again the implied mean elapsed tenure for each year. As shown in Figure 9 this has surprisingly little effect on the time pattern of the average tenure. However, if we also restrict the number of new entrants to a constant the pattern is very different irrespective of whether we keep the hazard rates constant or not. Note that even if both the entry rate and the hazard rates are constant, average elapsed duration generally changes over time since there is no reason to assume that the tenure distribution in 1963 reflected a steady state. In fact, the mean elapsed duration of ongoing jobs in 1963 was rather low, possibly due to earlier labor supply shocks.

\footnotetext{
${ }^{3}$ The model used for the simulation exercise includes only duration dependence and year effects with no unobserved heterogeneity.
} 

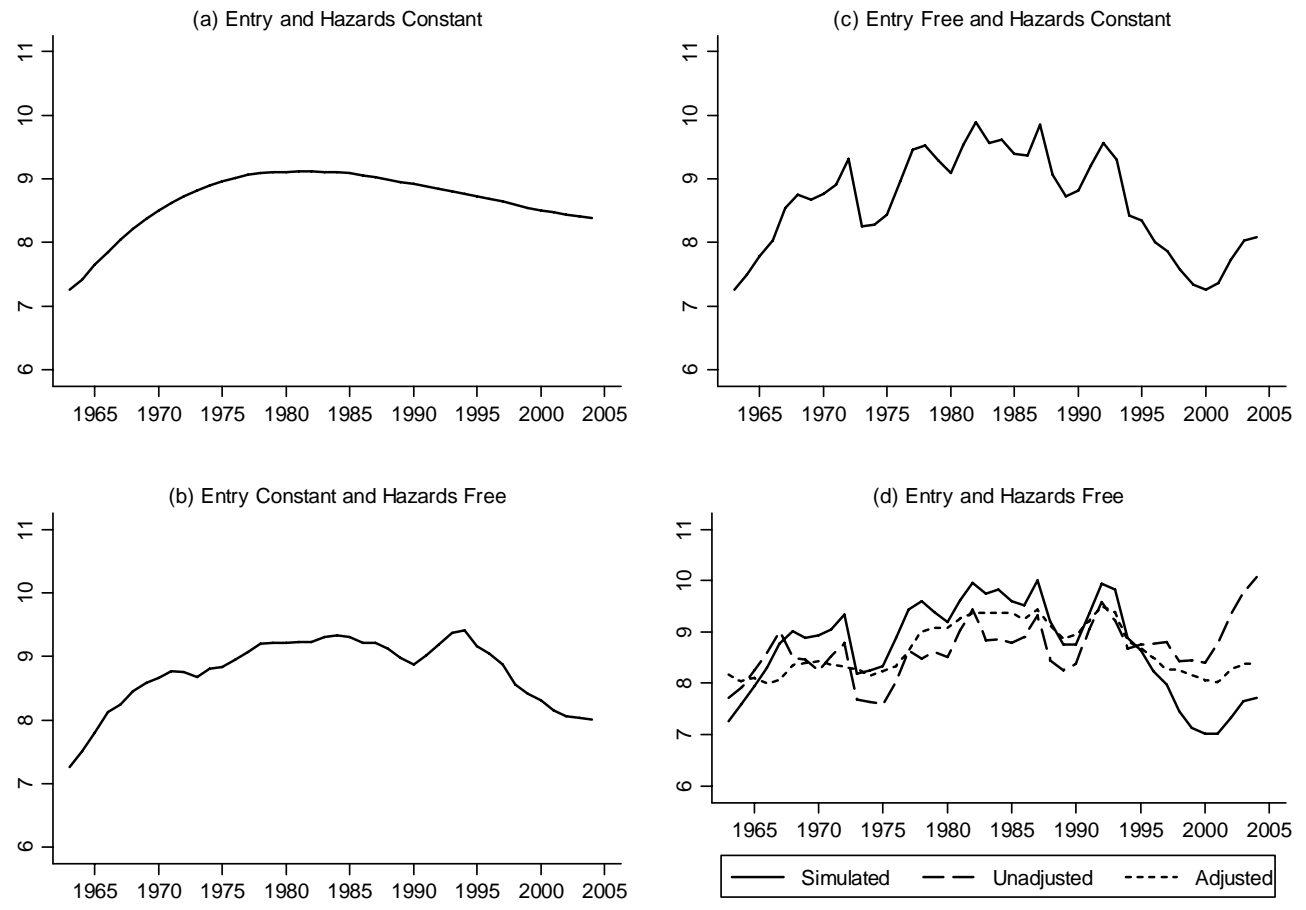

Figure 9 Simulation results 


\section{Lifetime jobs}

For the cohorts that have retired by the year 2004 we can directly observe the duration distribution for the longest job over the career. In Figure 10 we present the average length of the longest job during the career for cohorts born in 1940 or before. For the cohorts for which we observe almost the entire career this can be done accurately. For the two oldest cohorts that are under observation from ages 53 or 58 onwards we can be less certain that the job we observe in the end of the career is the longest job the individual has held over lifetime. To make the data more consistent between cohorts we restrict the data to those who were employed at some point after age 50.

According to Figure 10 the average length of the longest job over lifetime in these cohorts was around 22 years for men and a few years shorter for women. For men the average length has been very similar across cohorts born between 1905 and 1940. For women there is a clear upward trend with the 1940 cohort reaching almost the same length as men. We have also calculated various quantiles of this distribution. For example the median durations are very close to the mean durations, both in terms of the level and changes.

Our results reveal that, at least for the cohorts that have already retired, long-term employment contracts were an important feature of the labor market. Also no indications that lifetime contracts had become less common can be seen in the data. Rather the long-term contracts seem to have gotten more common, at least for women, perhaps reflecting their increased participation into the labor market. 


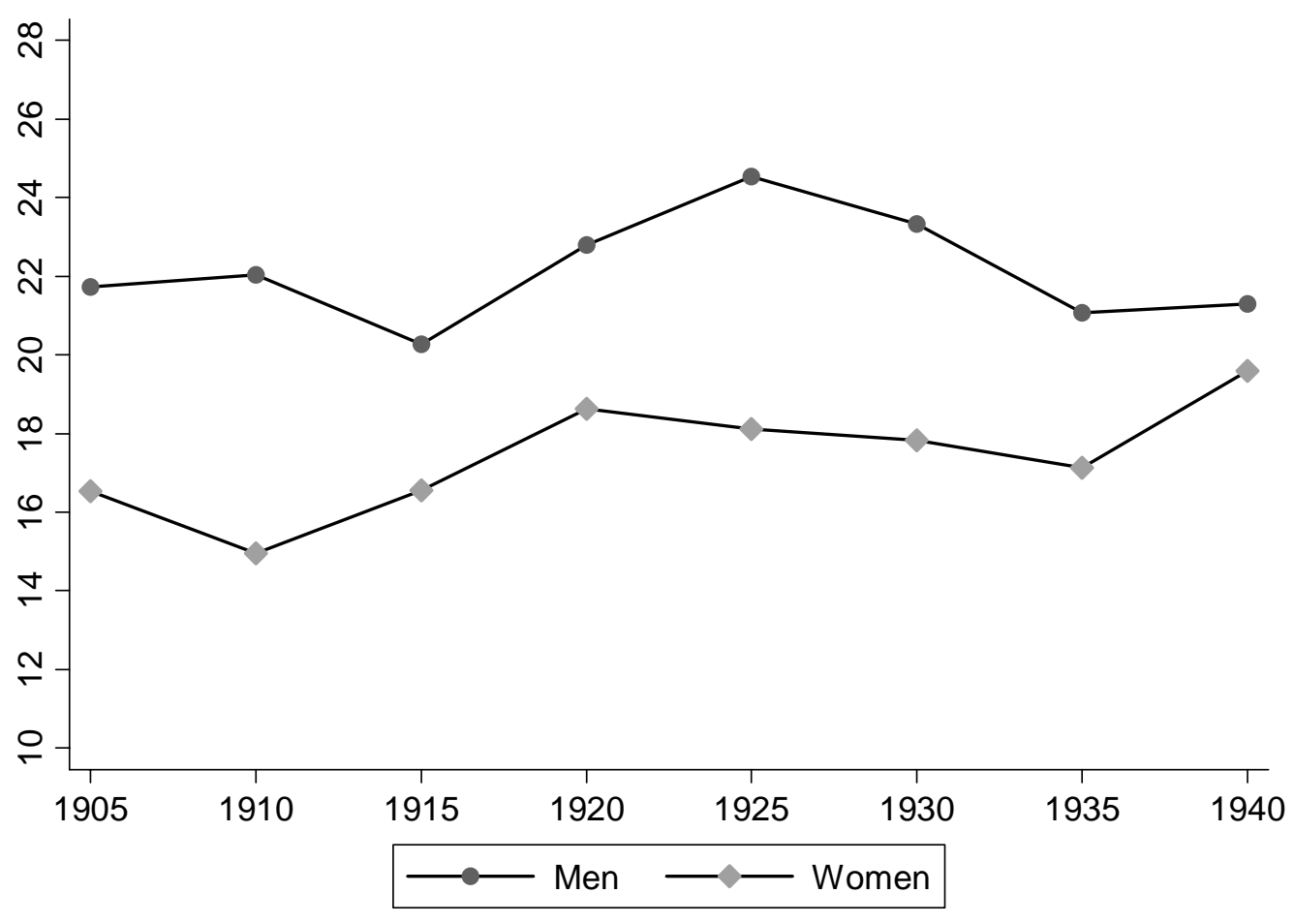

Figure 10 Average length of longest job during the career 


\section{Conclusions}

The estimates presented in this paper suggest that there has been no long-term trend in the mean elapsed duration of ongoing jobs in Finland. Average tenure has still varied considerably over time, but this variation has been mainly due to the variation in the number of new entrants into the labor market. If we instead measure job market stability by the hazard of job loss - or more precisely by the hazard of job ending that leads into non-employment - using a standard duration model specification, we find that job stability declined during a major recession but that the risk of job loss after year 2000 is at the level observed forty years ago.

Our results suggest that there are important caveats to be kept in mind when using the elapsed duration of ongoing jobs to measure changes in job stability. The changes in average tenure appear to be mainly related to the changes in the number of new jobs rather than changes in stability of existing jobs.

This paper also illustrates the benefits of using register data originally collected for administrative purposes. Pension registers are particularly useful since calculating pensions typically requires information from the entire careers. Compared with previous research on job stability we can both cover much longer period starting from early 1960s to present and observe the entire lifetime job histories. The Finnish data is of unusual quality because of centrally coordinated pension system that requires information on dates of employment contracts. Still similar data probably exists with pension authorities also in other countries. 


\section{References}

Bansak, C. \& Raphael, S. 2006. Have Employment Relationships in the United States Become Less Stable? International Advances in Economic Research 12, 342-357.

Bergemann, A. \& Mertens, A. 2004. Job Stability Trends, Layoffs and Transitions to Unemployment - An Empirical Analysis for West Germany. Centre for Economic Policy Research. Discussion Paper 4792.

Bernhardt, A., Morris, M., Handcock, M. S. \& Scott, M. A. 2000. Trends in Job Instability and Wages for Young Adult Males. In Neumark, D. (eds.) On the Job: Is Long-term Employment a Thing of the Past? New York: Russel Sage Foundation, 111141.

Booth, A. L., Francesconi, M. \& Garcia-Serrano, C. 1999. Job Tenure and Mobility in Britain. Industrial and Labor Relations Review 53 (1), 43-70.

Bratberg, E., Salvanes, K. G. \& Vaage, K. 2006. Has Job Stability Decreased in Norway? University of Bergen. Working Paper 74.

Brown, J. N. \& Light, A. 1992. Interpreting Panel Data on Job Tenure. Journal of Labor Economics 10 (3), 219-257.

Burgess, S. \& Rees, H. 1996. Job Tenure in Britain 1975-1992. The Economic Journal 106 (435), 334-344.

Burgess, S. \& Rees, H. 1997. Transient Jobs and Lifetime Jobs: Dualism in the British Labour Market. Oxford Bulletin of Economics and Statistics 59 (3), 309-328.

Burgess, S. \& Rees, H. 1998. A Disaggregated Analysis of the Evolution of Job Tenure in Britain, 1975-1993. British Journal of Industrial Relations 36 (4), 629-655.

Diepold, F. X., Neumark, D \& Polsky, D. 1997. Job Stability in the United States. Journal of Labor Economics 15 (2), 206-233.

Farber, H. S. 1995. Are Lifetime Jobs Disappearing? Job Duration in the United States: 1973-1993. National Bureau for Economic Research. Working Paper 360. 
Farber, H. S. 1997. Trends in Long Term Employment in the United States, 1979-96. Princeton University. Working Paper 384.

Farber, H. S. 2007. Is the Company Man an Anachronism? Trends in Long Term Employment in the U.S., 1973-2006. Princeton University. Working Paper No. 518.

Gottschalk, P. \& Moffit, R. A. 2000. Job Instability and Insecurity in the 1980s and 1990s. In Neumark, D. (eds.) On the Job: Is Long-term Employment a Thing of the Past? New York: Russel Sage Foundation, 142-195.

Gregg, P. \& Wadsworth, J. 1995. A Short History of Labour Turnover, Job Tenure, and Job Security, 1975-93. Oxford Review of Economic Policy 11 (1), 73-90.

Gregg, P. \& Wadsworth, J. 2002. Job Tenure in Britain, 1975-2000. Is a Job for Life or Just for Christmas? Oxford Bulletin of Economics and Statistics 64 (2), 111-134.

Hall, R. E. 1982. The Importance of Lifetime Jobs in the U.S. Economy. The American Economic Review 72 (4), 716-724.

Heckman, J. \& Singer, B. 1984. A Method for Minimizing the Impact of Distributional Assumptions in Econometric Models for Duration Data. Econometrica 52 (2), 271-320.

Heisz, A. 1999. Changes in Job Duration in Canada. Industrial Relations 54 (2), 365387.

Heisz, A. 2005. The Evolution of Job Stability in Canada: Trends and Comparisons with U.S. Results. Canadian Journal of Economics 38 (1), 105-127.

Jaeger, D. A. \& Stevens, A. H. 2000. Is Job Stability in the United States Falling? Reconciling Trends in the Current Population Survey and Panel Study of Income Dynamics. In Neumark, D. (eds.) On the Job: Is Long-term Employment a Thing of the Past? New York: Russel Sage Foundation, 31-69.

Lancaster, T. 1979. Econometric Methods for the Duration of Unemployment. Econometrica 67(4), 939-956. 
Mahringer, H. 2005a. Recent Trends in Job Stability: Evidence from Austrian Social Security Records. In Mahringer, H. Essays on Child Care Costs and Mothers' Employment Rates and on Job Stability. University of Linz, 49-86.

Mahringer, H. 2005b. Trends in Job Stability and Destinations of Job Endings as Competing Risks. In Mahringer, H. Essays on Child Care Costs and Mothers' Employment Rates and on Job Stability. University of Linz, 87-144.

Marcotte, D. 1999. Has Job Stability Declined? Evidence from the Panel Study of Income Dynamics. American Journal of Economics and Sociology 58 (2), 197-216.

Neumark, D., Polsky, D. \& Hansen, D. 2000. Has Job Stability Declined Yet? New Evidence for the 1990s. In Neumark, D. (ed.) On the Job: Is Long-term Employment a Thing of the Past? New York: Russel Sage Foundation, 70-110.

Neumark, D. (ed.) 2000. On the Job: Is Long-term Employment a Thing of the Past? New York: Russel Sage Foundation.

OECD 2007. Employment Outlook 2007. Paris OECD.

Polsky, D. 1999. Changing Consequences of Job Separation in the United States. Industrial and Labor Relations Review 52 (4), 565-580.

Sousa-Poza, A. 2004. Job Stability and Job Security: A Comparative Perspective on Switzerland's Experience in the 1990s. European Journal of Industrial Relations 10 (1), $31-49$.

Stevens, A. H. 2005. The More Things Change, the More They Stay the Same: Trends in Long-term Employment in the United States, 1969-2002. National Bureau for Economic Research. Working Paper 11878.

Stewart, J. 2002. Recent Trends in Job Stability and Job Security: Evidence from the March CPS. U.S. Bureau of Labor Statistics. Working Paper 356.

Swinnerton, K. A. \& Wial, H. 1995. Is Job Stability Declining in the U.S. Economy? Industrial and Labor Relations Review 48 (2), 293-304. 
Ureta, M. 1992. The Importance of Lifetime Jobs in the U.S. Economy, Revisited. The American Economic Review 82 (1), 322-335.

Vejsiu, A. 2001. Job Tenure in Sweden 1968-1998. In Vejsiu, A. Essays on Labor Market Dynamics. Economic Studies 56. Uppsala University, 11-50.

Winkelmann, R. \& Zimmermann, K. F. 1998. Is Job Stability Declining in Germany? Evidence from Count Data Models. Applied Economics 30 (11), 1413-1420. 
Appendix

Parameter Estimates for the Mixed Proportional Hazard Competing Risks Model of Job Endings

\begin{tabular}{|c|c|c|c|c|c|c|}
\hline & \multicolumn{3}{|c|}{ To Non-Employment } & \multicolumn{3}{|c|}{ To a New Job } \\
\hline & Estimate & SE & P-value & Estimate & SE & P-value \\
\hline Constant & 1.626 & 0.147 & 0.000 & -0.938 & 0.203 & 0.000 \\
\hline Male & -0.195 & 0.033 & 0.000 & -0.023 & 0.035 & 0.258 \\
\hline \multicolumn{7}{|c|}{ Duration depencence (reference category 0) } \\
\hline 4 months & -0.534 & 0.037 & 0.000 & -0.242 & 0.057 & 0.000 \\
\hline 8 months & -0.995 & 0.043 & 0.000 & -0.303 & 0.063 & 0.000 \\
\hline 1 year & -1.482 & 0.042 & 0.000 & -0.697 & 0.057 & 0.000 \\
\hline 2 years & -1.848 & 0.051 & 0.000 & -0.927 & 0.065 & 0.000 \\
\hline 3 years & -2.002 & 0.057 & 0.000 & -1.094 & 0.073 & 0.000 \\
\hline 4 years & -2.291 & 0.069 & 0.000 & -1.234 & 0.082 & 0.000 \\
\hline 5 years & -2.268 & 0.073 & 0.000 & -1.462 & 0.092 & 0.000 \\
\hline 6 years & -2.385 & 0.079 & 0.000 & -1.532 & 0.099 & 0.000 \\
\hline 7 years & -2.567 & 0.091 & 0.000 & -1.631 & 0.108 & 0.000 \\
\hline 8 years & -2.620 & 0.097 & 0.000 & -2.038 & 0.135 & 0.000 \\
\hline 9 years & -2.591 & 0.104 & 0.000 & -1.892 & 0.136 & 0.000 \\
\hline 10 years & -2.613 & 0.109 & 0.000 & -1.525 & 0.125 & 0.000 \\
\hline 11 years & -2.646 & 0.125 & 0.000 & -2.012 & 0.162 & 0.000 \\
\hline 12 years & -2.646 & 0.120 & 0.000 & -2.424 & 0.199 & 0.000 \\
\hline 13 years & -2.664 & 0.127 & 0.000 & -2.108 & 0.179 & 0.000 \\
\hline 14 years & -2.742 & 0.135 & 0.000 & -2.203 & 0.195 & 0.000 \\
\hline 15 years & -2.570 & 0.131 & 0.000 & -2.208 & 0.219 & 0.000 \\
\hline 16 years & -2.799 & 0.151 & 0.000 & -2.182 & 0.205 & 0.000 \\
\hline 17 years & -2.673 & 0.139 & 0.000 & -2.508 & 0.266 & 0.000 \\
\hline 18 years & -2.743 & 0.159 & 0.000 & -3.313 & 0.423 & 0.000 \\
\hline 19 years & -2.778 & 0.167 & 0.000 & -2.836 & 0.348 & 0.000 \\
\hline 20 years & -2.647 & 0.160 & 0.000 & -2.598 & 0.314 & 0.000 \\
\hline 21 years & -2.794 & 0.172 & 0.000 & -4.132 & 0.618 & 0.000 \\
\hline 22 years & -2.618 & 0.167 & 0.000 & -2.695 & 0.374 & 0.000 \\
\hline 23 years & -2.544 & 0.164 & 0.000 & -3.104 & 0.477 & 0.000 \\
\hline 24 years & -2.711 & 0.195 & 0.000 & -3.147 & 0.517 & 0.000 \\
\hline 25 years & -2.522 & 0.171 & 0.000 & -2.625 & 0.393 & 0.000 \\
\hline 26 years & -2.556 & 0.188 & 0.000 & -2.905 & 0.515 & 0.000 \\
\hline 27 years & -2.379 & 0.175 & 0.000 & -3.975 & 1.002 & 0.000 \\
\hline 28 years & -2.830 & 0.228 & 0.000 & -2.901 & 0.474 & 0.000 \\
\hline 29 years & -2.484 & 0.201 & 0.000 & -11.314 & 0.096 & 0.000 \\
\hline 30 years & -2.209 & 0.106 & 0.000 & -2.857 & 0.271 & 0.000 \\
\hline \multicolumn{7}{|c|}{ Year effects (reference category 1963) } \\
\hline 1964 & 0.022 & 0.111 & 0.421 & 0.115 & 0.178 & 0.259 \\
\hline 1965 & 0.066 & 0.109 & 0.273 & -0.121 & 0.187 & 0.258 \\
\hline 1966 & -0.025 & 0.114 & 0.415 & 0.189 & 0.178 & 0.144 \\
\hline 1967 & -0.161 & 0.118 & 0.085 & -0.367 & 0.198 & 0.032 \\
\hline 1968 & -0.112 & 0.110 & 0.153 & -0.079 & 0.182 & 0.332 \\
\hline 1969 & -0.271 & 0.117 & 0.010 & 0.047 & 0.176 & 0.395 \\
\hline 1970 & -0.199 & 0.117 & 0.044 & 0.091 & 0.174 & 0.300 \\
\hline 1971 & -0.307 & 0.124 & 0.007 & 0.158 & 0.173 & 0.179 \\
\hline 1972 & -0.256 & 0.108 & 0.009 & 0.526 & 0.152 & 0.000 \\
\hline 1973 & -0.085 & 0.096 & 0.186 & 0.311 & 0.148 & 0.018 \\
\hline 1974 & -0.225 & 0.103 & 0.014 & 0.480 & 0.144 & 0.000 \\
\hline 1975 & -0.329 & 0.109 & 0.001 & 0.011 & 0.165 & 0.473 \\
\hline 1976 & -0.152 & 0.113 & 0.090 & -0.035 & 0.167 & 0.416 \\
\hline
\end{tabular}




\begin{tabular}{|c|c|c|c|c|c|c|}
\hline 1977 & -0.118 & 0.111 & 0.145 & -0.275 & 0.190 & 0.074 \\
\hline 1978 & -0.103 & 0.107 & 0.168 & 0.079 & 0.157 & 0.306 \\
\hline 1979 & -0.128 & 0.106 & 0.115 & 0.252 & 0.156 & 0.053 \\
\hline 1980 & -0.161 & 0.112 & 0.075 & 0.191 & 0.163 & 0.121 \\
\hline 1981 & -0.130 & 0.114 & 0.127 & 0.219 & 0.169 & 0.098 \\
\hline 1982 & 0.043 & 0.106 & 0.342 & 0.229 & 0.165 & 0.083 \\
\hline 1983 & 0.084 & 0.100 & 0.202 & 0.398 & 0.151 & 0.004 \\
\hline 1984 & 0.005 & 0.103 & 0.482 & 0.494 & 0.148 & 0.000 \\
\hline 1985 & -0.061 & 0.109 & 0.286 & 0.445 & 0.158 & 0.002 \\
\hline 1986 & 0.047 & 0.110 & 0.335 & 0.380 & 0.159 & 0.008 \\
\hline 1987 & 0.086 & 0.111 & 0.219 & 0.590 & 0.155 & 0.000 \\
\hline 1988 & 0.029 & 0.098 & 0.384 & 0.710 & 0.139 & 0.000 \\
\hline 1989 & -0.035 & 0.100 & 0.363 & 0.718 & 0.141 & 0.000 \\
\hline 1990 & 0.117 & 0.103 & 0.128 & 0.323 & 0.154 & 0.018 \\
\hline 1991 & 0.229 & 0.110 & 0.018 & -0.071 & 0.173 & 0.341 \\
\hline 1992 & 0.590 & 0.102 & 0.000 & -0.147 & 0.181 & 0.207 \\
\hline 1993 & 0.593 & 0.095 & 0.000 & -0.110 & 0.165 & 0.253 \\
\hline 1994 & 0.188 & 0.099 & 0.030 & 0.131 & 0.156 & 0.201 \\
\hline 1995 & 0.283 & 0.103 & 0.003 & 0.084 & 0.157 & 0.296 \\
\hline 1996 & 0.187 & 0.105 & 0.038 & 0.110 & 0.156 & 0.242 \\
\hline 1997 & 0.048 & 0.101 & 0.317 & 0.503 & 0.149 & 0.000 \\
\hline 1998 & 0.105 & 0.094 & 0.131 & 0.418 & 0.137 & 0.001 \\
\hline 1999 & 0.024 & 0.098 & 0.404 & 0.339 & 0.142 & 0.008 \\
\hline 2000 & -0.077 & 0.099 & 0.220 & 0.373 & 0.145 & 0.005 \\
\hline 2001 & -0.104 & 0.105 & 0.162 & 0.308 & 0.150 & 0.020 \\
\hline 2002 & -0.018 & 0.100 & 0.429 & 0.259 & 0.147 & 0.039 \\
\hline 2003 & 0.000 & 0.099 & 0.498 & 0.219 & 0.145 & 0.065 \\
\hline 2004 & -0.073 & 0.115 & 0.264 & 0.309 & 0.166 & 0.031 \\
\hline \multicolumn{7}{|c|}{ Age effects (reference category 23) } \\
\hline 24 & 0.024 & 0.057 & 0.334 & -0.029 & 0.086 & 0.367 \\
\hline 25 & -0.162 & 0.066 & 0.007 & 0.118 & 0.097 & 0.111 \\
\hline 26 & -0.213 & 0.068 & 0.001 & -0.100 & 0.104 & 0.169 \\
\hline 27 & -0.345 & 0.063 & 0.000 & -0.210 & 0.088 & 0.009 \\
\hline 28 & -0.476 & 0.063 & 0.000 & -0.126 & 0.081 & 0.061 \\
\hline 29 & -0.368 & 0.070 & 0.000 & -0.175 & 0.093 & 0.030 \\
\hline 30 & -0.494 & 0.081 & 0.000 & -0.081 & 0.106 & 0.220 \\
\hline 31 & -0.563 & 0.084 & 0.000 & -0.191 & 0.110 & 0.042 \\
\hline 32 & -0.585 & 0.075 & 0.000 & -0.150 & 0.096 & 0.060 \\
\hline 33 & -0.564 & 0.070 & 0.000 & -0.200 & 0.093 & 0.016 \\
\hline 34 & -0.552 & 0.082 & 0.000 & -0.106 & 0.101 & 0.148 \\
\hline 35 & -0.593 & 0.089 & 0.000 & -0.196 & 0.116 & 0.045 \\
\hline 36 & -0.526 & 0.086 & 0.000 & -0.413 & 0.126 & 0.001 \\
\hline 37 & -0.584 & 0.082 & 0.000 & -0.230 & 0.114 & 0.022 \\
\hline 38 & -0.599 & 0.081 & 0.000 & -0.414 & 0.110 & 0.000 \\
\hline 39 & -0.488 & 0.085 & 0.000 & -0.302 & 0.117 & 0.005 \\
\hline 40 & -0.618 & 0.095 & 0.000 & -0.300 & 0.128 & 0.010 \\
\hline 41 & -0.604 & 0.098 & 0.000 & -0.345 & 0.135 & 0.005 \\
\hline 42 & -0.694 & 0.094 & 0.000 & -0.307 & 0.122 & 0.006 \\
\hline 43 & -0.609 & 0.089 & 0.000 & -0.312 & 0.113 & 0.003 \\
\hline 44 & -0.710 & 0.104 & 0.000 & -0.381 & 0.142 & 0.004 \\
\hline 45 & -0.523 & 0.105 & 0.000 & -0.456 & 0.157 & 0.002 \\
\hline 46 & -0.507 & 0.104 & 0.000 & -0.476 & 0.164 & 0.002 \\
\hline 47 & -0.650 & 0.101 & 0.000 & -0.463 & 0.143 & 0.001 \\
\hline 48 & -0.649 & 0.100 & 0.000 & -0.489 & 0.150 & 0.001 \\
\hline 49 & -0.632 & 0.109 & 0.000 & -0.649 & 0.168 & 0.000 \\
\hline 50 & -0.552 & 0.107 & 0.000 & -0.782 & 0.190 & 0.000 \\
\hline 51 & -0.527 & 0.110 & 0.000 & -0.982 & 0.221 & 0.000 \\
\hline 52 & -0.358 & 0.100 & 0.000 & -0.783 & 0.185 & 0.000 \\
\hline 53 & -0.373 & 0.099 & 0.000 & -0.666 & 0.194 & 0.000 \\
\hline
\end{tabular}




\begin{tabular}{ccccccc}
54 & 0.031 & 0.105 & 0.384 & -0.842 & 0.198 & 0.000 \\
55 & 0.066 & 0.106 & 0.267 & -0.891 & 0.221 & 0.000 \\
56 & 0.131 & 0.112 & 0.122 & -0.760 & 0.236 & 0.001 \\
57 & -0.047 & 0.108 & 0.334 & -0.903 & 0.237 & 0.000 \\
58 & 0.166 & 0.107 & 0.060 & -0.849 & 0.250 & 0.000 \\
59 & 0.631 & 0.109 & 0.000 & -1.015 & 0.301 & 0.000 \\
60 & 0.495 & 0.120 & 0.000 & -1.001 & 0.373 & 0.004 \\
61 & 0.718 & 0.123 & 0.000 & -0.550 & 0.313 & 0.039 \\
62 & 0.803 & 0.122 & 0.000 & -1.025 & 0.369 & 0.003 \\
63 & 0.859 & 0.124 & 0.000 & -1.177 & 0.429 & 0.003 \\
64 & 2.394 & 0.106 & 0.000 & -1.437 & 0.715 & 0.022 \\
Unobserved heterogeneity & & & & & & 0.000 \\
m2 & -0.330 & 0.215 & 0.062 & -1.915 & 0.139 & 0.000 \\
m3 & -1.034 & 0.171 & 0.000 & -1.016 & 0.074 & \\
p2 & 1.737 & 0.413 & 0.000 & & & \\
p3 & 1.465 & 0.275 & 0.000 & & & \\
\hline
\end{tabular}

Pseudo log-likelihood

$-4385653$

Notes: Maximum likelihood estimates using sampling weights. Standard errors based on Huber-White sandwhich estimator. 